\title{
Increasing Access to Task-Oriented Community-Based Exercise Programs Through Healthcare-Community Partnerships to Improve Function Post-Stroke: Feasibility of a 2-Group Randomized Controlled Trial Protocol
}

\author{
Gayatri Aravind \\ University of Toronto \\ Kainat Bashir \\ University of Toronto \\ Jill I. Cameron \\ University of Toronto \\ Jo-Anne Howe \\ Toronto Rehabilitation Institute \\ Susan B. Jaglal \\ University of Toronto \\ Mark T. Bayley \\ KITE-Toronto Rehabilitation Institute \\ Robert Teasell \\ Saint Joseph's Health Care London \\ Rahim Moineddin \\ University of Toronto \\ Joanne Zee \\ Toronto General Hospital \\ Walter Wodchis \\ University of Toronto \\ Alda Tee \\ Royal Victoria Regional Health Centre \\ Susan Hunter \\ Western University \\ Nancy Margaret Salbach ( $\square$ nancy.salbach@utoronto.ca ) \\ University of Toronto https://orcid.org/0000-0002-6178-0691
}

\section{Research}

Keywords: Community, Stroke, Randomized controlled trial, Task-oriented training, Healthcare-community partnership, Balance, Mobility, Everyday function

Posted Date: June 16th, 2021

DOI: https://doi.org/10.21203/rs.3.rs-599797/v1

License: @ (i) This work is licensed under a Creative Commons Attribution 4.0 International License. Read Full License 


\section{Abstract}

Background

Objectives were to describe the feasibility of a protocol for evaluating a community-based exercise program incorporating a healthcarecommunity partnership (CBEP-HCP) compared to a waitlist control group on improving everyday function among people post-stroke.

Methods

A pilot 2-group randomized controlled trial was conducted in three cities in Ontario, Canada. Adults ( $\geq 18$ years) living at home for $\geq 3$ months post-stroke, and able to walk $\geq 10$ metres without physical assistance were stratified by site and gait speed and randomly assigned to an exercise program or waitlist control group. Trained fitness instructors delivered a 1-hour, group exercise class, involving repetitive and progressive practice of balance/mobility tasks relevant to everyday function (e.g., sit-to-stand, walking, step-ups) twice a week for 12 weeks. The waitlist group was offered the exercise program at 10 months. Blinded assessors conducted evaluations at 3, 6 and 10 months postbaseline. Sensitivity to change of two measures of everyday function (Subjective Index of Physical and Social Outcome (SIPSO) and Nottingham Extended Activities of Daily Living (NEADL)) was compared. Qualitative interviews were conducted separately with 13 participants and 9 caregivers post-intervention. Quantitative and qualitative results were triangulated.

Results

Thirty-three people with stroke were randomized to the intervention ( $n=16)$ or waitlist group $(n=17) ; 68 \%$ of available caregivers agreed to participate. Recruitment rates were $2.4,1.2$, and 1.1 participants/month across sites and highest in the largest urban centre. Participants preferred a familiar healthcare professional to refer them to the study. Participants described a 10- or 12-month wait as too long and two people in the waitlist group withdrew for this reason. The exercise program was implemented per protocol across sites. Attendance was lowest (63\% and $71 \%$ in the intervention and waitlist group, respectively) at 10-month evaluations. Participants described inclement weather, availability of transportation, and long commutes as barriers to attending evaluations and exercise classes. The SIPSO physical scale but not the NEADL detected change in the intervention group. Quantitative and qualitative results suggested an immediate effect of the intervention on balance, balance self-efficacy, everyday function (dressing, cooking), and overall health.

Conclusion

Challenges with recruitment, attendance, and retention will inform protocol revisions for a future trial.

Trial Registration: ClinicalTrials.gov, NCT03122626. Registered April 17, 2017 - Retrospectively registered, https://www.clinicaltrials.gov/ct2/show/NCT03122626

\section{Key Messages Regarding Feasibility}

\section{What uncertainties existed regarding the feasibility?}

a. Will recruitment of participants and caregivers, data collection, and interventions be feasible in small, medium, and large urban cities?

b. Which outcome measures will be most sensitive to change in participants' abilities to perform everyday functions?

c. Will it be feasible to identify and train fitness instructors and volunteers to deliver the program?

\section{What are the key feasibility findings?}

a. Participant recruitment was feasible but had lowest yields in small and medium centres. Recruitment of discharged patients was more successful when conducted by a healthcare professional that had previously been within the circle of care compared to a research assistant. People post-stroke considered the recruitment approach and materials acceptable. Not all available caregivers were recruited potentially because recruitment materials did not highlight benefits of participation. Some control group participants found waiting 12 months for the exercise program unacceptably long and select individuals withdrew for this reason. Participants considered program and evaluation schedules to be acceptable; however, inclement weather, limited accessible transportation options, and availability of caregivers posed barriers to attendance.

b. The physical scale of the Subjective Index of Physical and Social Outcome (SIPSO) and Barthel Index detected the greatest change in everyday function from baseline to post-intervention in the experimental group.

c. Some recreation centres do not have the infrastructure to find volunteers. Turnover of volunteers and fitness instructors due to alternative assignments or leaves of absence necessitated training of new instructors and volunteers.

3. What are the implications of the feasibility findings for the design of the main study?

Page 2/24 
a. Healthcare professionals within the circle of care should refer individuals to the study through in-person hospital-based or telephonebased recruitment. Caregiver recruitment materials should highlight the potential benefits of study participation for people post-stroke and caregivers. A 6-month wait time for the waitlist control group may minimize withdrawal.

b. The SIPSO physical scale may be an optimal measure of the effect of the intervention on everyday function as it incorporates basic and instrumental activities of daily living.

c. Training back-up fitness instructors may address challenges with reassignment, staff turnover, and limited availability of volunteers.

d. Funds to support transportation (volunteer driver, private adapted transportation etc.) for participants who are unable to drive or who live in areas without adapted transportation services are needed.

\section{Background}

Stroke remains a leading cause of long-term disability worldwide [1]. In Canada alone, over 400,000 people are living with the effects of stroke a number that is estimated to reach 726,000 by 2038 [2]. After a stroke, people often experience balance and walking limitations [3-6] which contribute to decreased function in everyday activities, including basic and instrumental activities of daily living (ADL) [7]. Reduced function has broad consequences. It negatively affects participation in meaningful activities, and health-related quality of life (HRQL) while increasing the need for caregiver assistance [8]. Decreased instrumental ADL function is also a significant predictor of hospitalization, home healthcare and social services utilization, and institutionalization in older adults $[9,10]$.

Although regular exercise participation following the rehabilitation phase would help to maintain or improve function, people post-stroke face barriers, personal (e.g., insufficient knowledge of how to exercise, fear of an adverse event, embarrassment, and lack of motivation [11-13]) and environmental (e.g., inadequate building/equipment access, insufficient instructor training/expertise, program cost, and lack of transportation) $[12,14]$ to engaging in mainstream fitness programs. To address these barriers, community-based exercise programs (CBEPs) tailored to the needs of people with stroke have been developed [15-19]. These programs commonly incorporate group, task-oriented training that involves the practice of functional activities, such as sit-to-stand, standing weight-shifts, and walking, for several reasons. Task-oriented training is effective in increasing balance, walking, cognition, and HRQL post-stroke [15, 19-22]. Task-oriented training is feasible to implement in recreation settings by non-regulated fitness personnel as the exercises involve practice of familiar activities with straightforward progressions, and minimal human and equipment resources and costs when exercises are organized in a circuit [22]. Exercising in groups helps fosters selfefficacy to perform functional tasks, social interaction, and motivation to exercise [23]. Furthermore, partnerships with healthcare professionals can facilitate education and training for the community centre staff on stroke-related impairments and functional limitations and tailoring exercises to participant needs $[24,25]$.

Despite the potential benefits of group, task-oriented CBEPs that incorporate a healthcare-community partnership, implementation is hindered by program cost, challenges training fitness instructors, staff turnover, and inadequate referral and transportation [26]. Evidence of effectiveness from a rigorously designed trial with an economic evaluation is needed to inform health and recreation policy and justify implementation of the program model to non-governmental, governmental, charitable, and healthcare organizations. This evidence, however, is scarce. Results from one randomized trial [15] conducted in the United Kingdom showed improvement in everyday function post-program that was maintained at one year. Influence on important outcomes, such as balance, mobility, participation, injurious falls, and caregiver assistance, is unknown. There is a need to incorporate strategies, such as stratification on physical function, a known strong confounder [27], monitoring of co-interventions, and adjustment for clustering and confounding in the analysis, to optimize methodological rigour.

\section{Together in Movement and Exercise (TIME ${ }^{\mathrm{MM}}$ ) Program}

$\mathrm{TIME}^{\mathrm{TM}}$ is a 12-week, community-based exercise program incorporating a healthcare-community partnership (CBEP-HCP) licensed by the University Health Network (UHN) $[18,28]$. In this partnership, a healthcare professional provides standardized training to fitness instructors to deliver a group, task-oriented exercise program targeting balance and mobility in community centres. A healthcare professional (typically a physical therapist), called the healthcare partner, visits the exercise program to observe and provide feedback to instructors. People with balance and mobility limitations must be able to walk at least 10 meters with or without mobility devices, without assistance from another person., to participate. Involvement of a healthcare professional to train instructors and visit the program appears to help safeguard the safety and health benefits of the program [25]. Participants and caregivers perceive that balance, core and leg strength, and confidence improve following the program, which contributes to improved walking, stairs ability, transfers, ADL function, participation in social and leisure activities, and reduced caregiver assistance [18, 23]. Evidence of safety and feasibility of the training and exercise program has been reported [18]. To date, however, a randomized controlled trial of this program model has not been undertaken in Canada to provide evidence that would help to influence widespread implementation, funding, and policy.

Prior to launching a large-scale trial, a pilot randomized controlled trial is required to assess methodological feasibility and acceptability of the study protocol, including the TIME ${ }^{\mathrm{TM}}$ program model, in small and large centres. Thus, the purpose of this study was to evaluate the feasibility of

Page $3 / 24$ 
a two-group randomized controlled trial protocol designed to evaluate the effectiveness of the TIME ${ }^{\mathrm{TM}}$ program compared to usual care in improving everyday function in ambulatory people discharged home post-stroke in small, and large urban centres. Secondary outcomes included life-space mobility, social participation, health-related quality of life (HRQL), caregiver assistance, caregiver emotional health and fatigue, and injurious falls. Explanatory outcomes included balance capacity, balance self-efficacy, lower limb strength, walking speed, walking capacity, frailty, cognition, and depression. Process evaluations are an important component of randomized controlled trials [29]. It is advisable to use qualitative and quantitative approaches to understand the experiences with the study protocol and the study results [29]. Specific objectives were to: 1) evaluate the feasibility and acceptability of the study protocol (recruitment, data collection, interventions) among community-dwelling people with stroke and caregivers; 2) describe the immediate and long-term effects of a 12-week, group task-oriented CBEP-HCP on primary and secondary outcome measures among community-dwelling people with stroke and their caregivers; and 3) identify an outcome measure of everyday function based on sensitivity to change.

\section{Methods}

\section{Study design}

A two parallel-group, mixed methods, pilot randomized controlled trial was conducted in two large (Toronto, and London) and one small (Pembroke) urban centre in Ontario, Canada from March 2017 to April 2019. Research ethics approval was obtained at each hospital site and the University of Toronto. Our reporting follows the CONSORT guideline [30]. A qualitative descriptive approach [31] was used to complement quantitative data to evaluate the feasibility and acceptability of the study protocol and effects of the exercise program.

\section{Eligibility and recruitment}

In each urban centre, a hospital with designated stroke rehabilitation beds and a physical therapist willing to serve as a healthcare partner formed a partnership with a recreation centre. Hospital managers identified a registered physical therapist with at least one year of experience treating people with stroke and invited them to fulfil the role of the healthcare partner. Healthcare partners were expected to attend fitness instructor training sessions, train volunteers (where available), observe five TIME ${ }^{\text {TM }}$ classes in a 24-class session and provide a 15minute debrief to fitness instructors after the observed class. Recreation centres that were located within $50 \mathrm{~km}$ of the hospital to facilitate healthcare partner visits, fully accessible, in close proximity to public transport, with an appropriately-sized multi-purpose room, and recreation programming for all ages and abilities, were considered eligible. Recreation managers identified three fitness instructors meeting the following criteria: group fitness instructor certifications, including CanFitPro ${ }^{\mathrm{TM}}$ Fitness Instructor Specialist, YMCA-Fitness Leadership, Ontario Fitness Council (OFC), American Council on Exercise (ACE), or equivalent; excellent communication and leadership skills; empathy, enthusiasm and a genuine interest in working with people with disability; and two volunteers to assist with set-up and takedown of equipment, and supervise exercises in the walking station. Healthcare and recreation staff participating in the study provided signed informed consent.

The principal investigator (author NMS) and a TIME ${ }^{T M}$ expert (author $\mathrm{JH}$ ) conducted separate orientation meetings with each hospital and recreation provider. Meetings involved viewing a video of the TIME ${ }^{T M}$ program [32], reviewing study documentation, including “Facts about TIME $^{\text {TM" [28], an article on safety, feasibility and potential benefit of TIME }}{ }^{T M}$ [18], list of equipment and resource needs, license and participant waiver, a list of research team members, 1-page study summary, a list of costs covered by the grant, and the study timeline.

The target population was ambulatory adults living in the community post-stroke. Inclusion criteria were: 1) clinical diagnosis of stroke documented in the health record; 2) age $\geq 18$ years; 3 ) living at home for at least 3 months post-hospitalization for stroke to allow sufficient time to transition to community living; 4) self-reported ability to walk $\geq 10$ metres with or without walking aids without assistance from another person; 5) ability to follow verbal instructions and speak and read English as judged by the recruiter; and 6) willingness to sign a liability waiver verifying medical clearance from a healthcare provider, and noting that TIME ${ }^{\mathrm{TM}}$ was intended as a wellness program, not as rehabilitation or physical therapy. Exclusion criteria were: 1) self-reported involvement in another exercise or rehabilitation program; 2) self-reported conditions or symptoms (e.g., unstable cardiovascular disease, significant joint pain) preventing exercise participation; 3 ) cognitive or behavioural deficits that would prevent cooperation within a group, as judged by the recruiter; 4) self-reported ability to walk $\geq 20$ minutes without a seated rest; and 5) self-reported ability to manage environmental barriers (curbs, ramps, and stairs) with relative ease.

Caregivers of consenting participants were considered eligible if they: 1) helped the individual post-stroke to live at home and provided support and assistance with at least one basic and /or instrumental ADLs at least once a week [33]; and 2) were able to speak and read English. Paid personal support workers were excluded.

Recruitment strategies were hospital-dependent. In Toronto, prospective and retrospective recruitment methods were used. A physical therapist distributed study brochures to in- and outpatients and their caregivers (March-September 2017) and screened for eligibility at the time of discharge. Another physical therapist contacted discharged outpatients seen October 2016-January 2017 by phone to screen for eligibility and gauge interest to participate. The Toronto-based study coordinator followed up by phone to obtain verbal informed consent, and scheduled 
baseline evaluations. In Pembroke, a nurse practitioner on the stroke team contacted individuals with stroke who received outpatient rehabilitation between January 2016 and January 2017 by phone, mailed brochures and consent forms to interested individuals and caregivers, obtained verbal informed consent, and scheduled baseline evaluations. In London, a research assistant contacted individuals with stroke who were inpatients or outpatients January 2016 to June 2017 by phone and mail, obtained verbal informed consent, and scheduled baseline evaluations. Individuals with stroke and caregivers provided written informed consent at the baseline evaluation.

\section{Data collection}

Both quantitative and qualitative data were collected to address all study objectives. Trained evaluators, blinded to study hypotheses and group assignment, completed evaluations at $0,3,6$, and 12 months at the hospital site. Coordinators made at least three attempts to schedule an evaluation at each time point. After baseline, participants were given the choice of completing self-report measures at home with each followup evaluation to reduce the length of the in-person evaluation.

Primary outcome: Everyday function was assessed using the Subjective Index of Physical and Social Outcome (SIPSO) [34] and the Nottingham Extended Activities of Daily Living (NEADL) [35]. The SIPSO is a 10-item self-report questionnaire comprising two 5-item subscales developed to capture physical (e.g., dressing, daily activities at home) and social (e.g., communication, satisfaction with friendships) integration post-stroke [34]. Participants score each activity from 0 to 4 where a higher score indicates a better level of integration. Subscale and total scores can range from 0 to 20 and 0 to 40, respectively. In community-dwelling people with stroke, intraclass correlation coefficient (ICC) values were 0.91 indicating excellent test-reliability of subscale and total scores. Correlations of scores on the SIPSO and the Barthel Index, Frenchay Activities Index, and Wakefield Depression Inventory ranging from 0.73 to 0.80 support the construct validity of SIPSO [34].

The NEADL is a 22-item, self-report measure of IADL performance with 4 scales: mobility, kitchen, domestic, and leisure. Item-level scores range from 0 to 3 where 0 indicates "unable" and 3 indicates "on my own". Total scores can range from zero to 66 . Spearman correlations of repeated measures using the subscales and total score ranging from 0.83 to 0.93 indicate a high level of test-retest reliability [36] and correlations of 0.88-0.90 with scores on the Barthel Index and Frenchay Activities Index provide evidence of construct validity in community-dwelling people with stroke [37].

Explanatory outcomes: Balance, balance self-efficacy, lower limb strength, walking distance, comfortable walking speed, cognition, and depression were evaluated using the Berg balance scale (BBS) [38], activities-specific balance confidence (ABC) scale [39], 30-second timed sitto-stand test (30-STS) [40], 6-minute walk test (6MWT) [41, 42], 10-metre walk test (10mWT) [43], trail making test (TMT) [44], and geriatric depression scale-short version (GDS) [45], respectively.

Secondary outcomes: Lifespace mobility and independence with basic ADL were evaluated using the Lifespace Assessment (LSA) [46], and the 10-item Barthel Index (BI) [47] respectively. HRQL was evaluated using the Stroke Impact Scale (SIS) [48], and the Euroqol-5D-5L (EQ-5D-5L) [49, 50], respectively. The Lifespace Assessment scale assesses how far and how often individuals have mobilized in their immediate and distant living environment within the past 4 weeks. The EQ-5D-5L captures dimensions of mobility, self-care, usual activities, pain/discomfort, and anxiety/depression, and converts to a single index value that can be used to calculate quality-adjusted life years (QALYs). A visual analog scale (EQ-VAS) yields a rating of current health that can range from 0 to 100 points. Caregiver assistance was assessed using the 17-item, self-report Caregiver Assistance Scale (CAS) [51, 52]. Caregiver emotional health was evaluated using the Research ANd Development-36 (RAND-36) emotional well-being and energy/fatigue score [53]. An injurious fall was defined as "an unexpected event in which the participant comes to rest on the ground, floor, or lower-level" [54] which results in an injury requiring medical care [55]. Participants were provided with monthly falls log calendars, and asked to record the occurrence of falls. The study coordinator or the evaluators contacted participants monthly to identify fall occurrence and determine if the fall led to injury requiring medical care. This approach is the gold standard method to prospectively evaluate falls [54]. At each evaluation, participants were asked to report on participation in co-interventions (e.g., physical therapy, alternate exercise classes) since the last evaluation.

At baseline, we collected data on participant age, sex, education level, employment status, income level, presence of caregiver, side of stroke, time post-stroke, comorbidity (Charlson comorbidity Index [56]), frailty (Canadian study of health and aging frailty scale [57]), type of mobility aids and orthoses used, as well as age, sex, role, employment status, and time spent caregiving of participating caregivers.

Intervention fidelity was evaluated by documenting implementation of TIME ${ }^{\mathrm{TM}}$ program elements, including the license, training (instructors, healthcare partners, volunteers), class frequency/duration, exercise class components (warm-up, specific exercises, cool down, recommended equipment, participant-to-instructor ratio), and healthcare partner visits. Fitness instructors documented adverse events that occurred during exercise classes using a standardized form. Participant engagement was evaluated by documenting attendance

We invited exercise and caregiver participants to separately participate in site- and intervention- specific focus groups or interviews that lasted approximately 45 to 60 minutes by telephone after the three-month evaluation. The research coordinator (KB) conducted all interviews. KB is a 
female and has a Master of Arts degree in Human Kinetics and 6 years of experience in conducting qualitative research. Participants were asked about their experiences with recruitment, evaluations, the exercise program (immeditate group), and waiting time (waitlist group), to understand the feasibility and acceptability of the study protocol and effects of the intervention. Sessions were digitally recorded, professionally transcribed verbatim, and reviewed for accuracy.

\section{Randomization}

Participants were stratified by site, and level of comfortable gait speed deficit (severe: $\leq 0.5 \mathrm{~m} / \mathrm{s}$; mild-moderate: $>0.5 \mathrm{~m} / \mathrm{s}$ ) and block randomized to either the TIME ${ }^{\mathrm{TM}}$ program (i.e., immediate group) or the waitlist group in a 1-to-1 allocation ratio after the baseline evaluation. $\mathrm{A}$ Toronto-based research assistant, unfamiliar with participants, prepared a list of randomization assignments for each site by flipping a coin (block size of 2). The Toronto-based research assistant revealed group allocation to each participant by phone. We stratified by gait speed as it has been previously shown to modify the effect of task-oriented training on walking capacity post-stroke [27]. Blocking was used to balance the size of study groups to maximize statistical efficiency [58].

\section{Intervention}

The program involves two one-hour exercise classes per week for 12 weeks. Each one-hour class involves a seated warm-up, repetitive and progressive practice of functionally relevant balance and mobility tasks, and a seated cool down. Warm-up consists of active range-of-motion exercises, aerobic exercise, lower extremity weight bearing, stretching, and sit-to-stand training. The cool-down involves exercises similar to the warm-up but with an emphasis on stretching and relaxation. Participants, grouped by ability level, complete exercises organized in a 3-station circuit as follows: station 1: walking, aerobic training, and wall work (standing and reaching, wall push-ups); station 2: standing weight shifts, stepping and lunging; and station 3: tap-ups, step-ups, and heel/toe raises, hamstring curls, marching-on-the-spot, and mini-squats. Each exercise has several levels of challenge to enable tailoring. Instructors are asked to use their judgement to gauge readiness and safety of to move participants to more challenging levels. Instructors are advised to have participants exercise at an intensity of 3-4 (moderate to somewhat hard) on the modified Borg scale [59]. The class is modeled after task-oriented interventions delivered by healthcare professionals with evidence of safety, feasibility, and efficacy from randomized trials involving people post-stroke [16, 27, 60-62]. Caregivers of participants with severe motor deficits are encouraged to attend and assist during the class.

After signing the license, the recreation provider received an electronic toolkit with materials required to implement the program. Materials included the participant referral form and liability waiver, exercise guideline, equipment/resource list, and measures to use for program evaluation. TIME ${ }^{\mathrm{TM}}$ trainers delivered a 6-hour in-person training workshop with fitness instructors and healthcare partners that involved describing the program model, the roles of the partners, and movement challenges experienced by exercise class participants, and review and practice of the exercises including all levels of challenge. Volunteers were trained separately. They were asked to view a video of the TIME ${ }^{\mathrm{TM}}$ program, review the exercise guideline, and complete a 1.5 hour session with the healthcare partner or a fitness instructor to review the program, their role and responsibilities, and practice the exercises in the walking station.

Healthcare partners were instructed to visit the first 2 classes to advise fitness instructors on participant grouping, safety considerations and exercise modifications, and three more classes spread out over the remaining 11 weeks of the program, and address any questions from the fitness instructors by email or phone. The waitlist group received usual care, and were offered to participate in the 3-month exercise program following the final evaluation.

\section{Sample size}

A sample size of 20 participants and their caregivers if available per site for a total sample size of 60 was proposed. The exercise class runs with a group size of 8-12 participants. Thus, a sample size of 60 was considered sufficient to enable trialing of the exercise program in small and large urban centres with a similar group size to that planned for the exercise program in the definitive cross-Canada trial. A sample size of 30 participants per group provided $80 \%$ power to detect an effect size of 0.72 (given SD=1 for the SIPSO-Physical).

\section{Analysis}

Feasibility of recruitment was evaluated by computing site-specific recruitment rates (number recruited/recruitment period in months) and the percentage of caregivers agreeing to participate. Feasibility of retention and data collection was summarized using percentages of individuals in each group withdrawing, completing evaluations, and providing monthly falls data. Intervention fidelity was reported as the number of sites implementing program elements, the number and percentage of classes delivered, the percentage of classes in which the prescribed classformat (i.e., warm up, recommended exercises, cool-down) were followed. Participant engagement was determined by the percentage of classes attended. The number of participants receiving co-interventions was noted. 
As this was a pilot study, we did not test hypotheses related to the effectiveness of the TIME ${ }^{\text {TM }}$ program compared to usual care. Participant data were analyzed in the group to which participants were randomized. We summarized scores on each outcome measure by group using medians and $25^{\text {th }}$ and $75^{\text {th }}$ percentiles for continuous data and with frequencies and percentages for categorical data at each evaluation time point. The risk of injurious falls during $\mathrm{TIME}^{\mathrm{TM}}$ classes was estimated by computing the absolute risk difference (i.e., proportion of participants in the immediate group with an injurious fall minus proportion of participants in the waitlist group with an injurious fall). For a multi-item measure, if more than $10 \%$ of the items were missing data, the entire measure was considered missing. If $\leq 10 \%$ of items were missing, missing values were replaced by the average across other items in the scale and the total score was calculated. To identify the optimal measure of everyday function, we compared the effect size of ADL measures if data were normally distributed; otherwise, we examined change in scores from baseline to 3 months.

Transcripts were entered into NVivo to assist wtih the organization and analysis of the data. Using a directed content analysis [63], transcripts were coded based on the protocol element (i.e., recruitment, data collection, and interventions), or the effect of the intervention, using a deductive approach. Authors KB and NMS independently reviewed and coded two transcripts and then met to discuss coding. KB then coded the remaining transcripts using NVivo10. Rigor was optimized by triangulating results from participants and caregivers and quotations were used to support identified themes. Results from quantitative and qualitative analyses for each objective were compared and contrasted to enhance the rigor and robustness of the analysis.

\section{Results}

Across sites, 33 individuals with stroke (i.e., participants) and 13 caregivers consented to participate. Sixteen participants with 8 caregivers were randomized to the TIME ${ }^{T M}$ program, and 17 participants with 5 caregivers were randomized to the waitlist group. Table 1 presents baseline sociodemographic and clinical characteristics of participants and caregivers by intervention group.

Figure 1 describes the flow of participants through the trial. Participants remained in the group to which they were assigned. Thirteen participants ( 8 from immediate and 5 from waitlist group) and 9 caregivers ( 5 from immediate and 4 from waitlist group) from across sites participated in 16 interviews or focus groups to share their experiences. Participants were 55-83 years of age, and included 8 men and 5 women who had attended either $3(n=2)$ or $4(n=11)$ evaluations. Those in the TIME ${ }^{T M}$ program attended $72 \%$ of exercise classes. Caregivers were 44 72 years of age, and included 5 men and 4 women. One caregiver was a child and eight caregivers were spouses.

\section{Recruitment-quantitative}

Across the 3 sites, 155 individuals with stroke were screened for eligibility. The period of recruitment was 7 months in Toronto and Pembroke and 6 months in London. Recruitment rates in Toronto, Pembroke, and London were 2.4, 1.2, and 1.1 participants/month, respectively. Of the 19 participants who had a caregiver, $13(68 \%)$ agreed to participate.

\section{Recruitment-qualitative}

A majority of participants reported having no preference for the method of initial contact (i.e., in-person vs. phone vs. mail) but indicated that having a member of their healthcare team recruiting facilitated their decision to enroll. Participants expressed the need for recruiters to describe the type, and benefits of the TIME ${ }^{\mathrm{TM}}$ exercises to facilitate decision making. Caregivers indicated that recruitment materials did not clearly explain the caregiver's role in the study. They recommended developing caregiver-specific recruitment materials that highlighted the social and physical health benefits of the program, and the opportunity for caregivers to participate in the exercise program to support their care recipient and/or "learn some of the moves" to practice them at home.

"He's in the house with me 24/7... He doesn't get to see anyone else all day long. ... when I joined the study, I thought, okay, this is his opportunity to get out and have some interaction with other people." S1CG-E1 (caregiver-immediate group)

\section{Retention-quantitative}

In the waitlist group, of the three withdrawals, two participants withdrew right after randomization as they were unwilling to wait 12 months to receive the intervention. For this reason, the research team decided mid-trial to reduce the wait period to 10 months. Prior to the 10 -month evaluation, the research team withdrew a third participant (and their caregiver) who experienced significant decline in physical and cognitive ability, resulting in a final retention rate in the waitlist group of $82.4 \%$. Two people in the TIME ${ }^{\text {TM }}$ program group withdrew. One participant (and their caregiver) withdrew after the first class due to an exacerbated back injury. The research team withdrew a participant (and their caregiver) prior to the 10-month evaluation who experienced a significant decline in physical and cognitive abilities, resulting in a final retention rate of $87.5 \%$. 
Retained participants and caregivers in the waitlist group reported that it was acceptable to be randomized to the waitlist group. The majority described wait times of 3 to 6 months as acceptable. Wait times of 10 or 12 months were considered to be "too long" as there would be no improvement if participants would be "sitting around doing nothing", particularly when added to the time needed to start up the study.

\section{Data collection-quantitative}

Table 2 provides an overview of the participant and caregiver attendance at evaluations, completion of falls monitoring, and participant involvement in co-interventions during the study duration. In the immediate group, at the 3-month evaluation, two participants were receiving physical therapy for a second stroke (3 times/week), shoulder pain (1 time/week), and one participant was doing a home exercise program for a severe foot drop. Between the 3- and 6-month evaluations, two individuals were participating in a group pool exercise program at a recreation centre. In the waitlist group, between the 3- and 6-month evaluations, three participants received physical therapy to improve their stroke recovery, and one person enrolled in a 3-month group exercise program at a recreation centre.

\section{Data collection-qualitative}

Participants reported that attending four evaluations was acceptable. A phone call reminder a few days in advance of the evaluations was considered helpful. Some participants described the evaluations as lengthy and tiring, with repetition of some questions across questionnaires. Some preferred completing questionnaires online or over the phone prior to the evaluations, while others preferred completing them in-person so they could ask clarifying questions.

\section{$T M^{T M}$ program implementation-quantitative}

Table 3 describes characteristics of participating recreation and healthcare centres, program delivery staff, and TIME ${ }^{\mathrm{TM}}$ program intervention fidelity. Recreation staff from all sites and the healthcare partner from Toronto and Pembroke attended one-day training workshops. TIMETM trainers oriented the London-based healthcare partner by Skype. Healthcare partners trained two volunteers in Toronto, and four volunteers in London. The Pembroke site chose not to recruit volunteers. Because of delays with obtaining ethics approval, program start in London was delayed, and instructors and volunteers were assigned to other programs. The recreation manager recruited four new fitness instructors, and a volunteer (a retired physical therapist) who completed an e-learning module that reviewed knowledge-based content of the original workshop and a 3-hour training workshop. One instructor went on leave prior to delivery of the exercise program in the waitlist group at one site necessitating training of a new instructor.

In the TIME ${ }^{\mathrm{TM}}$ program group, 5 of the 16 participants attended fewer than $50 \%$ of the classes (median attendance $=4 \%$; range $4-45 \%$ ) for health reasons that included a new diagnosis of stage 5 melanoma $(n=1)$; swollen feet and blisters $(n=1)$; recurrent stroke $(n=1)$; fall while attending a medical appointment leading to hip fracture and surgical repair $(n=1)$; and an inability to attend two classes a week due to extreme fatigue $(n=1)$. One participant withdrew from the study. For the other 10 participants, median attendance was $92 \%$ (range $72-100 \%)$. No injuries or incidents related to the intervention were reported.

\section{TIME $^{T M}$ program implementation-qualitative}

Across sites, participants and caregivers made positive comments about instructors, describing them as empathetic, encouraging, and welltrained to teach and tailor the difficulty level of exercises to participant ability level, adapt exercises when necessary, and challenge participants in a safe manner. One participant commented:

They didn't make us feel like we were stroke victims or anything. We were just normal people having an exercise program. They were very awesome about that. Like they didn't discriminate on anybody's level or anything. S2P-C1 (participant-waitlist control)

Some participants at the Toronto and London sites found visits from a familiar healthcare partner reassuring. One participant commented:

Oh, she was watching everything and making sure everything was going right. She encouraged people too... She knew most of us because I remember her from the [name] Clinic. She did her job...maybe suggested a few things to the instructors. But she was good. S3P-E1 (participant-immediate group)

At all sites, some participants described challenges related to accessibility that decreased the acceptability of program delivery. Challenges included an inadequate number of accessible parking spots, entrances inaccessible due to construction, and the occasional malfunction of accessible doors. At one site, the two weekly classes were held in different rooms which caused some confusion. At another site, the class was run in a fitness studio where another fitness class was occasionally run concurrently which was distracting. 
Participants across sites described challenges with transportation to the program and evaluations. Challenges includes long, tiring commutes (1.5-2 hours one-way), transferring transit systems, and delays or no-shows of public transit services. Driving in snowy or icy weather conditions, cost of hiring a driving service or a personal support worker to accompany them further impacted participants' abilities to attend the program. Nevertheless, participants and caregivers at all sites expressed a willingness to commute long distances to access the program due to its potential benefits, and the lack of similar programs in their communities. One participant commented:

Yeah, for me it's an hour and a half from door to door... it's either go or don't go... to be honest, the call was going to be sure, we'll try it a couple of times. If it's... a waste of time, you know, if we don't feel it's beneficial, we're going to pull the plug. But it was worthwhile so we bit the bullet and drove 3 hours a day to go. S2P-E1 (participant-immediate group)

Recommendations included increasing the class duration to make a long commute worthwhile, offering more sessions per week, running the program during good weather months, and providing a home-based program. One caregiver described the challenges of attending the program during cold weather:

Like even taking him to the [recreation centre] in the wintertime, like it was freezing there. So...it would be better...to have [these programs] in the nice weather as opposed to like say December until March. They should start in April and go until like maybe the end of October. It's easier for the people to get around...Because... some people are in walkers and wheelchairs...so in the wintertime, it's a little hard for them. S1CG-E1 (caregiver-immediate group)

\section{Potential effect-quantitative}

To evaluate potential immediate and sustained effects, we excluded from the analysis five participants in the immediate group who did not attend at least $50 \%$ of the classes due to serious health conditions; five participants with missing data as they withdrew from the study ( $\mathrm{n}=2$ from immediate group, and $n=3$ from waitlist group); and two participants in the waitlist group who did not attend any follow-up evaluations. Data from 8 participants and 6 caregivers in the immediate group, and 13 participants and 5 caregivers in the waitlist group were analyzed. Table 1 presents baseline characteristics and Table 4 presents median scores on outcome measures at each evaluation by intervention group. Compared to participants in the waitlist group at baseline, participants in the immediate group were older and had lower median scores on measures of physical function including the BBS; STS test, 10mWT, and 6WMT. Scores on primary outcome measures of everyday function were not normally distributed. Change from 0 to 3 months in median score on the SIPSO and NEADL in the immediate vs waitlist group were: SIPSO-Physical (3 vs 0 points); SIPSO-Social (-2 vs -1 points); and NEADL: (-3 vs 10 points). The gains in median score on secondary outcome measures from 0 to 3 months in the immediate (vs waitlist group) were largest for EQ-5D-5L health utility (0.2 vs -0.1$)$; EQ-VAS (20 vs 10 points); SIS recovery VAS (23 vs -5 points); SIS hand function (7 vs 1 point); and Barthel Index (15 vs 0 points). Compared to the waitlist group, the median score on explanatory outcome measures increased in the immediate group to a greater extent from 0 to 3 months for the BBS, ABC scale, 30-STS, and TMT-A, but not the 6MWT, 10mWT, or TMT-B. No injurious falls occurred during exercise classes. One participant in the waitlist group experienced an injurious fall in month four while performing usual activities and sought the advice of their physician.

\section{Potential effect-qualitative}

A majority of participants and caregivers in the immediate group described a range of benefits of the TIME ${ }^{\mathrm{TM}}$ program. These included providing participants with a meaningful activity and an opportunity to socialize. Access to a formal program motivated participants to exercise, and reinforced caregivers' efforts to engage the participant in physical activity. A majority of participants described improvements in their mobility, such as walking longer distances at faster speeds and with better form. Participants noted greater confidence and independence while walking while caregivers observed improvements in participants' balance, transitions to using a less supportive walking aid (e.g., walker to cane), with benefits extending to daily activities, such as cooking, dressing. One participant noted:

And my balance was improved that I could do more things around the house. Like stand at the kitchen counter and cut up the onions and things for dinner, and start doing more of that. S2P-E1 (participant-immediate group)

Caregivers did not describe any reduction in the level of assistance they provided the care recipient as a result of program participation. They appreciated the opportunity to exercise alongside their family member to "be involved" and provide motivation to be more active. One caregiver commented:

It's a win-win situation. You know, it builds up his physical and mental... strengths that he has it in him...And for me, I see that it's good for him. Like I'm seeing that he's actually showing an honest interest [in exercising]. S2CG-C1 (caregiver-waitlist control)

Caregivers who waited together outside the exercise class reported bonding over sharing similar experiences. One participant who primarily used a wheelchair and their caregiver reported not experiencing any change as a result of their participation in the program, possibly due to the 
participant's low baseline status. Table 5 summarizes the challenges that were observed during the pilot study and the proposed changes to the protocol of the definitive RCT based on researcher observation and feedback from participants.

\section{Discussion}

This study is the first to explore the feasibility and acceptability of a 2-group, RCT protocol designed to evaluate the TIME ${ }^{\mathrm{TM}}$ program in people post-stroke in Canada. We identified protocol challenges that included a lengthy wait time in the waitlist group, and recruitment, evaluation, and retention of individuals with stroke. Participants and caregivers largely perceived the TIME ${ }^{\text {TM }}$ program as beneficial in improving balance, strength, mobility, and everyday functioning. We identified the physical component of the SIPSO as the optimal outcome measure of everyday function.

\section{Feasibility and acceptability of study protocol}

Rates of participant and caregiver recruitment were low across sites. Recruitment led by a healthcare provider (in-person or over the telephone) within the circle of care was a more successful recruitment strategy compared to contact by a research assistant. Adding community-based strategies, such as posting advertisements in hospitals and churches, and including advertisements in seniors centre newsletters, to complement hospital-based strategies, may help bolster recruitment [64].

A 12-month waitlist control design, initially proposed to track study outcomes in the long-term, led to dropouts and was perceived as too long by participants and caregivers. In contrast, an RCT of a similar exercise program model with a 12-month waitlist group conducted in the United Kingdom involving 243 people post-stroke [15] completed data collection in $84 \%$ of participants at 6 months, and $71 \%$ at one year. This superior 12-month retention compared to the current study may have resulted from use of convenient home-based assessments, a smaller test battery, and limiting the 12-month evaluation to mailing of self-report questionnaires. In a recent pilot RCT of a community-based, task-oriented exercise program run three times a week in the United States [64], only 58\% of participants completed the 6-month intervention and evaluations compared to $70 \%$ of control group participants who received a 6-month seated exercise program. As in the current study, reasons for withdrawals included medical illness and transportation [64]. Reasons for even lower retention at one site included difficulty parking, lack of transportation, longer travel times, and lower socioeconomic status compared to other sites [64]. These factors highlight the implementation challenges of conducting a pragmatic trial of a CBEP in people with stroke who commonly experience additional health conditions [65]. For the definitive RCT, we propose a 6-month waitlist control, considered acceptable by many participants, and only three evaluations at 0 , 3 , and 6 months to minimize participant withdrawals. A 6-month waitlist may also help minimize participation in co-interventions which occurred to a similar degree in each group. To decrease evaluation burden, a parsimonious set of study measures will be achieved by eliminating duplicative measures of everyday function and the lengthy SIS. Providing transportation allowances, arranging for driving services or alternative modes of transportation for participants who are unable to drive, and scheduling the program outside of months with inclement winter weather may further minimize absenteeism and missing data.

Overall, the delivery of the CBEP-HCP in its intended format was feasible. All sites were able to organize the resources required to deliver the program. Instructor training was considered effective given participants and caregivers found the program safe, acceptable, and beneficial. Program challenges with room accessibility and availability can be addressed by scheduling classes at a consistent time and location.

\section{Program impact}

In the current study, only the magnitude of within-group change can be interpreted given the between-group differences in sociodemographic characteristics, physical function, and health at baseline among participants included in the treatment-received analysis. Participants in the immediate group showed meaningful changes in measures of hand function, lower limb strength, balance, mobility, and perception of extent of recovery at the end of the 3-month program compared to baseline status. While the greatest gains were seen at 3-month evaluations for most outcomes, participants in the immediate group continued to show improvements in leg strength, balance confidence, perception of extent of recovery at the 10-month evaluations.

Contrary to expectation, the immediate group did not improve in walking speed or endurance over time, despite self-reported improvements in balance confidence and reduced use of walking aids. In an RCT [64] of a similar group, task-oriented exercise CBEP run by exercise instructors three times a week for 6 months, a significant increase in 6MWT-based walking distance and speed, but not scores on the BBS, short performance physical battery [66], or SIS, was observed. When exercise classes have been provided only twice a week for 8 weeks, a significant increase in timed 'up and go' scores was not observed [15]. In the current study, fitness instructors at all sites and volunteers at one site were running the TIME ${ }^{\mathrm{TM}}$ exercise program for the first time and may not have sufficiently challenged participants. A strategy used in a previous RCT [64] to mitigate a lack of experience among novice exercise instructors involved providing an opportunity to instruct an initial group of participants prior to beginning randomization. This strategy, combined with incorporating more time to practice exercises during training, and exclusively employing fitness instructors, may help promote appropriate tailoring of exercise difficulty level to participant ability. 
An important design element of the program was the social interaction it afforded individuals with stroke facing similar challenges.

Participants in the immediate group, however, did not demonstrate improvement in social functioning on the SIPSO-Social scale. One explanation is that all participants were recruited from tertiary hospitals which serve large geographical areas and transportation was timeconsuming for many. In other TIME ${ }^{\mathrm{TM}}$ programs, recreation staff create opportunities for interactions (such as post-program social time, end-ofprogram potlucks [18]) which may help to create a sense of community with the other participants.

Caregivers in the immediate group, who described improvements in participants' balance, strength, and functioning, did not note reductions in caregiver assistance or improvement in emotion/fatigue until the 10-month evaluation. It is possible that improvements were limited to performance of basic but not instrumental ADL which necessitated the continued assistance of the caregivers. Additionally, accompanying and driving participants to the $\mathrm{TIME}^{\mathrm{TM}}$ program twice a week might have offset any reductions in perceived caregiver burden resulting from improved ADL function.

Compared to the NEADL, participants in the immediate group showed greater median change on the SIPSO-Physical. The SIPSO [34], which is specific to stroke, measures physical and social reintegration after stroke and captures the level of difficulty faced when performing physical and social activities. Alternatively, the NEADL is intended to be used as a record of activity performed in the last few weeks with or without help [67]. The NEADL is vulnerable to influences of inclement weather and pandemic-related restrictions to maintain social distancing. Some activities included on the NEADL, such as writing a letter, may be viewed as outdated. Finally, the SIPSO has a 5-point response scale which may capture smaller gains compared to the 4-point response scale of the NEADL. For these reasons, the SIPSO would be the optimal measure of everyday function in the definitive trial.

\section{Limitations of the study}

Due to the small sample size obtained and missing data, only descriptive statistics could be performed to compare the effect of the program vs usual care on functional abilities of persons with stroke living in the community. Participants were not blinded to their group allocation which could have resulted in a bias, especially on self-report measures. The generalizability of the findings is limited by the use of strict eligibility criteria, as well as by issues related to seasonal program delivery (e.g., inclement weather) which affected attendance at the program and evaluations.

\section{Conclusions}

The CBEP-HCP was safe for post-stroke individuals living in the community, many of whom self-reported improvements in their ability to perform functional activities of daily living, along with improvements in their balance, strength and mobility. This pilot study revealed issues with feasibility and acceptability of the 2-group waitlist RCT protocol. The lessons learned will inform the protocol of the definitive RCT which will aim to assess the effectiveness of the CBEP-HCP program in improving everyday function among persons with stroke living in the community.

\section{Abbreviations}

10mWT, 10-meter walk test; 6MWT, 6-minute walk test; ADL, activities of daily living; adl; ABC, activities-specific balance confidence; BBS, Berg balance scale; Barthel index; $\mathrm{CCl}$, Charlson comorbidity index; CBEP-HCP, community-based exercise program -healthcare community partnership; GDS, geriatric depression scale; HRQOL, health-related quality of life; IADL, instrumental activities of daily living; ICC, intraclass correlation coefficient; ; LSA, life space assessment; NEADL, Nottingham extended activities of daily living; QALY, quality-adjusted life years; RCT, randomized controlled trial; SIPSO, subjective index of physical and social outcome; SIS, stroke impact scale; TIME ${ }^{\mathrm{T}}$, together in movement and exercise; TMT, trail making test; VAS, visual analogue scale

\section{Declarations}

Ethics - The health science research ethics board at the University of Toronto (34220), and the Scarborough and Rouge Hospital- Centenary Site Research Ethics Board (17-01-0001), Pembroke Regional Hospital Research Ethics Board (2017-002), Western University Health Science Research Ethics Board (109032) approved the study protocol. All participants received information regarding the study and signed an informed consent form.

Consent for publication - Not applicable.

Author's contributions - NMS was the project lead (PI) and was responsible for the conceptual development, study design, analysis, interpretation of results, and writing of all drafts; GA was responsible for the analysis of the quantitative and qualitative data, interpretation of results, and writing of all drafts; JIC guided evaluation of caregiver outcomes; SH was responsible for the approach to falls monitoring; RM was 
responsible for the approach to quantitative analysis; all others contributed to study design regarding their specialties, commented, and reviewed drafts. All authors read and approved the final manuscript.

\section{Funding}

This project was funded by the Heart and Stroke Foundation (G-16-00013979). They had no role in the design, analysis or writing the manuscript. NMS held a Heart and Stroke Foundation Mid-Career Investigator Award and the Toronto Rehabilitation Institute Chair at the University of Toronto to complete this work.

\section{Availability of data and materials}

The datasets generated and/or analyzed during the current study are not publicly available due to small numbers and possible identification of individuals, but are available from the corresponding author on reasonable request.

\section{Competing Interests}

$\mathrm{JH}$ is one of the lead developers of the TIME ${ }^{\mathrm{TM}}$ program but was not involved in data collection or data analysis.

\section{Consent for Publication}

Not applicable

\section{References}

1. Benjamin EJ, Muntner P, Alonso A, Bittencourt MS, Callaway CW, Carson AP, Chamberlain AM, Chang AR, Cheng S, Das SR, et al. Heart disease and stroke statistics-2019 update a report from the american heart. association Circulation. 2019;139(10):E56-28. https://doi.org/10.1161/Cir.0000000000000659.

2. Krueger H, Koot J, Hall RE, O'Callaghan C, Bayley M, Corbett D. Prevalence of individuals experiencing the effects of stroke in canada trends and projections. Stroke. 2015;46(8):2226-2231. https://doi.org/10.1161/Strokeaha.115.009616.

3. Tyson SF, Hanley M, Chillala J, Selley A, Tallis RC. Balance disability after stroke Phys Ther. 2006;86(1):30-8. https://doi.org/10.1093/ptj/86.1.30.

4. Jørgensen HS, Nakayama H, Raaschou HO, Olsen TS. Recovery of walking function in stroke patients: The copenhagen stroke study. Arch Phys Med Rehabil. 1995;76(1):27-32. https://doi.org/10.1016/s0003-9993(95)80038-7.

5. Friedman PJ. Gait recovery after hemiplegic stroke. Int Disabil Stud. 1990;12(3):119-22. https://doi.org/10.3109/03790799009166265.

6. Latham NK, Jette DU, Slavin M, Richards LG, Procino A, Smout RJ, Horn SD. Physical therapy during stroke rehabilitation for people with different walking abilities. Arch Phys Med Rehabil. 2005;86(12 Suppl 2):41-s50. https://doi.org/10.1016/j.apmr.2005.08.128.

7. Mayo NE, Wood-Dauphinee S, Côté R, Durcan L, Carlton J. Activity, participation, and quality of life 6 months poststroke. Arch Phys Med Rehabil. 2002;83(8):1035-42. https://doi.org/10.1053/apmr.2002.33984.

8. Scholte op Reimer WJ, de Haan RJ, Rijnders PT, Limburg M, van den Bos GA. The burden of caregiving in partners of long-term. stroke survivors Stroke. 1998;29(8):1605-11. https://doi.org/10.1161/01.str.29.8.1605.

9. Bharucha AJ, Pandav R, Shen C, Dodge HH, Ganguli M. Predictors of nursing facility admission: A 12-year epidemiological study in the united states. J Am Geriatr Soc. 2004;52(3):434-9. https://doi.org/10.1111/j.1532-5415.2004.52118.x.

10. Dodge HH, Belle SH, Morycz RK, Rodriguez E, Lytle M, Ganguli M. Functional and demographic predictors of health and human services utilization: a community-based study. J Am Geriatr Soc. 1999;47(10):1271-3. https://doi.org/10.1111/j.1532-5415.1999.tb05215.x.

11. Elsworth C, Dawes H, Sackley C, Soundy A, Howells K, Wade D, Hilton-Jones D, Freebody J, Izadi H. A study of perceived facilitators to physical activity in neurological conditions. Int J Ther Rehabil. 2009;16(1):17-24. https://doi.org/10.12968/ijtr.2009.16.1.37936.

12. Rimmer JH, Riley B, Wang E, Rauworth A, Jurkowski J. Physical activity participation among persons with disabilities: barriers and facilitators. Am J Prev Med. 2004;26(5):419-25. https://doi.org/10.1016/j.amepre.2004.02.002.

13. Rimmer JH, Wang E, Smith D. Barriers associated with exercise and community access for individuals with stroke. J Rehabil Res Dev. 2008;45(2):315-22. https://doi.org/10.1682/jrrd.2007.02.0042.

14. Fullerton A, Macdonald M, Brown A, Ho PL, Martin J, Tang A, Sibley KM, Mcllroy WE, Brooks D. Survey of fitness facilities for individuals post-stroke in the greater toronto area. Appl Physiol Nutr Metab. 2008;33(4):713-9. https://doi.org/10.1139/H08-037.

15. Harrington R, Taylor G, Hollinghurst S, Reed M, Kay H, Wood VA. A community-based exercise and education scheme for stroke survivors: a randomized controlled trial and economic evaluation. Clin Rehabil. 2009;24(1):3-15. https://doi.org/10.1177/0269215509347437. 
16. Pang MYC, Eng JJ, Dawson AS, McKay HA, Harris JE. A community-based fitness and mobility exercise program for older adults with chronic stroke: a randomized, controlled trial. J Am Geriatr Soc. 2005;53(10):1667-74. https://doi.org/10.1111/j.1532-5415.2005.53521.x.

17. Richardson J, Tang A, Guyatt G, Thabane L, Xie F, Sahlas D, Hart R, Fleck R, Hladysh G, Macrae L. Fit for function: study protocol for a randomized controlled trial. Trials 2018;19. https://doi.org/10.1186/s13063-017-2416-3.

18. Salbach NM, Howe JA, Brunton K, Salisbury K, Bodiam L. Partnering to increase access to community exercise programs for people with stroke, acquired brain injury, and multiple sclerosis. J Phys Act Health. 2014;11(4):838-45. https://doi.org/10.1123/jpah.2012-0183.

19. Stuart M, Benvenuti F, Macko R, Taviani A, Segenni L, Mayer F, Sorkin JD, Stanhope SJ, Macellari V, Weinrich M. Community-based adaptive physical activity program for chronic stroke: feasibility, safety, and efficacy of the empoli model. Neurorehabil Neural Repair. 2009;23(7):726-34. https://doi.org/10.1177/1545968309332734.

20. Rensink M, Schuurmans M, Lindeman E, Hafsteinsdottir T. Task-oriented training in rehabilitation after stroke: systematic review. J Adv Nurs. 2009;65(4):737-54. https://doi.org/10.1111/j.1365-2648.2008.04925.x.

21. Taricco M, Dallolio L, Calugi S, Rucci P, Fugazzaro S, Stuart M, Pillastrini P, Fantini MP. Impact of adapted physical activity and therapeutic patient education on functioning and quality of life in patients with postacute strokes. Neurorehabil Neural Repair. 2014;28(8):719-28. https://doi.org/10.1177/1545968314523837.

22. Wevers L, van de Port I, Vermue M, Mead G, Kwakkel G. Effects of task-oriented circuit class training on walking competency after stroke: a systematic review. Stroke. 2009;40(7):2450-9. https://doi.org/10.1161/STROKEAHA.108.541946.

23. Merali S, Cameron JI, Barclay R, Salbach NM. Experiences of people with stroke and multiple sclerosis and caregivers of a community exercise programme involving a healthcare-recreation partnership. Disabil Rehabil. 2020;42(9):1220-6. https://doi.org/10.1080/09638288.2018.1519042.

24. Merali S, Cameron JI, Barclay R, Salbach NM. Characterising community exercise programmes delivered by fitness instructors for people with neurological conditions: A. scoping review Health Soc Care Community. 2016;24(6):e101-16. https://doi.org/10.1111/hsc.12282.

25. Skrastins O, Tsotsos S, Aqeel H, Qiang A, Renton J, Howe JA, Tee A, Moller J, Salbach NM. Fitness coordinators' and fitness instructors' perspectives on implementing a task-oriented community exercise program within a healthcare-recreation partnership for people with balance and mobility limitations: a qualitative study. Disabil Rehabil. 20191-9. https://doi.org/10.1080/09638288.2019.1570357.

26. Salbach NM, Howe J-A, Baldry D, Merali S, Munce SEP. Considerations for expanding community exercise programs incorporating a healthcare-recreation partnership for people with balance and mobility limitations: a mixed methods evaluation. BMC Res Notes. 2018;11(1):214. https://doi.org/10.1186/s13104-018-3313-x.

27. Salbach NM, Mayo NE, Wood-Dauphinee S, Hanley JA, Richards CL, Cote R. A task-orientated intervention enhances walking distance and speed in the first year post stroke: a randomized controlled trial. Clin Rehabil. 2004;18509-519. https://doi.org/10.1191/0269215504cr763oa.

28. UHN. Together in movement and exercise (time ${ }^{\mathrm{tm}}$ ) http://www.uhn.ca/TorontoRehab/PatientsFamilies/Clinics_Tests/TIME.

29. Moore GF, Audrey S, Barker M, Bond L, Bonell C, Hardeman W, Moore L, O'Cathain A, Tinati T, Wight D, Baird J. Process evaluation of complex interventions: medical research council guidance BMJ. 2015;350h1258. https://doi.org/10.1136/bmj.h1258.

30. Thabane L, Hopewell S, Lancaster GA, Bond CM, Coleman CL, Campbell MJ, Eldridge SM. Methods and processes for development of a consort extension for reporting pilot randomized controlled trials. Pilot Feasibility Stud. 2016;225. https://doi.org/10.1186/s40814-0160065-z.

31. Sandelowski M. What's in a name? Qualitative description revisited. Res Nurs Health. 2010;33(1):77-84. https://doi.org/10.1002/nur.20362.

32. Time $^{\text {tm }}$ video 2015 https://www.youtube.com/watch?v=QtMyDvEREEg.

33. Dewey HM, Thrift AG, Mihalopoulos C, Carter R, Macdonell RA, McNeil JJ, Donnan GA. Informal care for stroke survivors: results from the north east melbourne stroke incidence study. (nemesis) Stroke. 2002;33(4):1028-33. https://doi.org/10.1161/01.str.0000013067.24300.b0.

34. Trigg R, Wood VA. The subjective index of physical and social outcome (sipso): a new measure for use with stroke patients. Clin Rehabil. 2000;14288-299. https://doi.org/10.1191/026921500678119607.

35. Gladman JR, Lincoln NB, Adams SA. Use of the extended adl scale with stroke patients. Age Ageing. 1993;22(6):419-424. https://doi.org/10.1093/ageing/22.6.419.

36. Nicholl CR, Lincoln NB, Playford ED. The reliability and validity of the nottingham extended activities of daily living scale in patients with multiple sclerosis. Mult Scler. 2002;8(5):372-6. https://doi.org/10.1191/1352458502ms827oa.

37. Sarker SJ, Rudd AG, Douiri A, Wolfe CD. Comparison of 2 extended activities of daily living scales with the barthel index and predictors of their outcomes: cohort study within the south london stroke register (. slsr) Stroke. 2012;43(5):1362-9. https://doi.org/10.1161/strokeaha.111.645234.

Page $13 / 24$ 
38. Berg K, Wood-Dauphinee S, Williams Jl. The balance scale: reliability assessment with elderly residents and patients with an acute stroke. Scand J Rehabil Med. 1995;27(1):27-36.

39. Myers AM, Fletcher PC, Myers AH, Sherk W. Discriminative and evaluative properties of the activities-specific balance confidence (abc) scale. J Gerontol A Biol. Sci Med Sci. 1998;53(4):M287-94. https://doi.org/10.1093/gerona/53a.4.m287.

40. Jones CJ, Rikli RE, Beam WC. A 30-s chair-stand test as a measure of lower body strength in community-residing older adults. Res Q Exerc Sport. 1999;70(2):113-9. https://doi.org/10.1080/02701367.1999.10608028.

41. Butland RJ, Pang J, Gross ER, Woodcock AA, Geddes DM. Two-, six-, and twelve-minute walking tests in respiratory disease. Br Med J (Clin Res Ed). 1982;284(6329):1607-8. https://doi.org/10.1136/bmj.284.6329.1607.

42. Salbach NM, O'Brien KK, Brooks D, Irvin E, Martino R, Takhar P, Chan S, Howe JA. Considerations for the selection of time-limited walk tests poststroke: a systematic review of test protocols and measurement properties. J Neurol Phys Ther. 2017;41(1):3-17. https://doi.org/10.1097/NPT.0000000000000159.

43. Cheng DK, Dagenais M, Alsbury-Nealy K, Legasto JM, Scodras S, Aravind G, Takhar P, Salbach NM. Distance-limited walk tests poststroke: A systematic review of protocols and measurement properties (in press). NeuroRehabilitation. 2021. https://doi.org/10.3233/NRE-210026.

44. Tamez E, Myerson J, Morris L, White DA, Baum C, Connor LT. Assessing executive abilities following acute stroke with the trail making test and digit span. Behav Neurol. 2011;24177-185. https://doi.org/10.3233/BEN-2011-0328.

45. Yesavage JA, Sheikh JI. 9/geriatric depression scale (gds). Clin Gerontol. 1986;5(1-2):165-173. https://doi.org/10.1300/J018v05n01_09.

46. Baker PS, Bodner EV, Allman RM. Measuring life-space mobility in community-dwelling older adults. J Am Geriatr Soc. 2003;51(11):16104. https://doi.org/10.1046/j.1532-5415.2003.51512.x.

47. Mahoney FI, Barthel DW. Functional evaluation: The barthel index. Md State Med J. 1965;1461-65.

48. Duncan PW, Wallace D, Lai SM, Johnson D, Embretson S, Laster LJ. The stroke impact scale version 2.0. Evaluation of reliability, validity, and sensitivity to change. Stroke. 1999;30(10):2131-40. https://doi.org/10.1161/01.STR.30.10.2131.

49. Herdman M, Gudex C, Lloyd A, Janssen M, Kind P, Parkin D, Bonsel G, Badia X. Development and preliminary testing of the new five-level version of eq-5d (eq-5d-5I). Qual Life Res. 2011;20(10):1727-36. https://doi.org/10.1007/s11136-011-9903-x.

50. Buchholz I, Janssen MF, Kohlmann T, Feng YS. A systematic review of studies comparing the measurement properties of the three-level and five-level versions of the eq-5d. Pharmacoeconomics. 2018;36(6):645-661. https://doi.org/10.1007/s40273-018-0642-5.

51. Cameron Jl, Franche RL, Cheung AM, Stewart DE. Lifestyle interference and emotional distress in family caregivers of advanced cancer patients. Cancer. 2002;94(2):521-7. https://doi.org/10.1002/cncr.10212.

52. Cameron JI, Cheung AM, Streiner DL, Coyte PC, Stewart DE. Stroke survivors' behavioral and psychologic symptoms are associated with informal caregivers'. experiences of depression Arch Phys Med Rehabil. 2006;87(2):177-83. https://doi.org/10.1016/j.apmr.2005.10.012.

53. Hays RD, Morales LS. The rand-36 measure of health-related quality of life. Ann Med. 2001;33(5):350-7. https://doi.org/10.3109/07853890109002089.

54. Lamb SE, Jørstad-Stein EC, Hauer K, Becker C. Development of a common outcome data set for fall injury prevention trials: the prevention of falls network europe consensus. J Am Geriatr Soc. 2005;53(9):1618-22. https://doi.org/10.1111/j.1532-5415.2005.53455.x.

55. Muir SW, Berg K, Chesworth B, Klar N, Speechley M. Balance impairment as a risk factor for falls in community-dwelling older adults who are high functioning: a prospective study. Phys Ther. 2010;90(3):338-47. https://doi.org/10.2522/ptj.20090163.

56. Tessier A, Finch L, Daskalopoulou SS, Mayo NE. Validation of the charlson comorbidity index for predicting functional outcome of stroke. Arch Phys Med Rehabil. 2008;89(7):1276-83. https://doi.org/10.1016/j.apmr.2007.11.049.

57. Rockwood K, Song XW, MacKnight C, Bergman H, Hogan DB, McDowell I, Mitnitski A. A global clinical measure of fitness and frailty in elderly people. Can Med Assoc J. 2005;173(5):489-95. https://doi.org/10.1503/cmaj.050051.

58. Piantadosi S. Clinical trials: a methodological perspective.. John Wilely \& Sons; 2005.

59. Wilson RC, Jones PW. A comparison of the visual analog scale and modified borg scale for the measurement of dyspnea during exercise. Clin Sci. 1989;76(3):277-82. https://doi.org/10.1042/cs0760277.

60. Dean CM, Richards CL, Malouin F. Task-related circuit training improves performance of locomotor tasks in chronic stroke: a randomized, controlled pilot trial. Arch Phys Med Rehabil. 2000;81409-417. https://doi.org/10.1053/mr.2000.3839.

61. Eng JJ, Chu KS, Kim CM, Dawson AS, Carswell A, Hepburn KE. A community-based group exercise program for persons with chronic stroke. Med Sci Sports Exerc. 2003;35(8):1271-8. https://doi.org/10.1016/j.apmr.2005.08.113.

62. Marigold DS, Eng JJ, Dawson AS, Inglis JT, Harris JE, Gylfadottir S. Exercise leads to faster postural reflexes, improved balance and mobility, and fewer falls in older persons with chronic stroke. J Am Geriatr Soc. 2005;53(3):416-23. https://doi.org/10.1111/j.15325415.2005.53158.x. 
63. Hsieh HF, Shannon SE. Three approaches to qualitative content analysis. Qual Health Res. 2005;15(9):1277-88.

https://doi.org/10.1177/1049732305276687.

64. Stuart M, Dromerick AW, Macko R, Benvenuti F, Beamer B, Sorkin J, Chard S, Weinrich M. Adaptive physical activity for stroke: an earlystage randomized controlled trial in the united states. Neurorehabil Neural Repair. 2019;33(8):668-80.

https://doi.org/10.1177/1545968319862562.

65. Gallacher KI, Batty GD, McLean G, Mercer SW, Guthrie B, May CR, Langhorne P, Mair FS. Stroke, multimorbidity and polypharmacy in a nationally representative sample of 1,424,378 patients in scotland: implications for treatment burden. BMC Med. $2014 ; 12151$. https://doi.org/10.1186/s12916-014-0151-0.

66. Guralnik JM, Ferrucci L, Pieper CF, Leveille SG, Markides KS, Ostir GV, Studenski S, Berkman LF, Wallace RB. Lower extremity function and subsequent disability: consistency across studies, predictive models, and value of gait speed alone compared with the short physical performance battery. J Gerontol A Biol Sci Med Sci. 2000;55(4):M221-31. https://doi.org/10.1093/gerona/55.4.m221.

67. Nouri FM, Lincoln NB. An extended adl scale for use with stroke patients. Clin Rehabil. 1987;1301 - 305. https://doi.org/10.1177/026921558700100409.

\section{Tables}

Table 1 Baseline characteristics of participants and caregivers randomized and included in the analysis by group 


\begin{tabular}{|c|c|c|c|c|}
\hline \multirow[t]{2}{*}{ Characteristic } & \multicolumn{2}{|l|}{ Randomized (n=33) } & \multicolumn{2}{|l|}{ Analyzed $(n=21)$} \\
\hline & $\begin{array}{l}\text { Immediate Group } \\
(\mathrm{n}=16)\end{array}$ & $\begin{array}{l}\text { Waitlist Group } \\
(n=17)\end{array}$ & $\begin{array}{l}\text { Immediate Group } \\
(\mathrm{n}=8)\end{array}$ & $\begin{array}{l}\text { Waitlist Group } \\
(n=13)\end{array}$ \\
\hline Age in years, Median $\left(\mathrm{P}_{25}, \mathrm{P}_{75}\right)$ & $71(65,80)$ & $67(58,79)$ & $72(66,80)$ & $65(57,79)$ \\
\hline No. (\%) female & $7(43)$ & $8(47)$ & $3(38)$ & $7(54)$ \\
\hline \multicolumn{5}{|l|}{ Level of Education } \\
\hline Secondary school or lower & $9(56)$ & $12^{\dagger}(70)$ & $4(50)$ & $9(75)$ \\
\hline College & $6(38)$ & $2(12)$ & $3(27)$ & $2(17)$ \\
\hline Graduate or Post-graduate & $1(6)$ & $1(6)$ & $1(13)$ & $1(8)$ \\
\hline No. (\%) employed & $1(6)$ & $1(6)$ & $1(6)$ & $1(6)$ \\
\hline \multicolumn{5}{|l|}{ Financial Status } \\
\hline Some money left over & $10(62)$ & $3(18)$ & $7(87)$ & $2(15)$ \\
\hline Just enough to make ends meet & $5(32)$ & $8(47)$ & $1(12)$ & $6(46)$ \\
\hline Not enough to make ends meet & $0(0)$ & $3(18)$ & $0(0)$ & $3(23)$ \\
\hline Refused to answer & $1(6)$ & $3(18)$ & $0(0)$ & $2(15)$ \\
\hline \multicolumn{5}{|l|}{ Side of Stroke, n (\%) } \\
\hline Right & $5(31)$ & $9^{*}(53)$ & $2(25)$ & $7(54)$ \\
\hline Left & $10(63)$ & $7(41)$ & $5(63)$ & $6(46)$ \\
\hline Bilateral & $1(6)$ & $0(0)$ & $1(12)$ & \\
\hline Months post-stroke, Median $\left(\mathrm{P}_{25}, \mathrm{P}_{75}\right)$ & $12(7,17)$ & $11(7,18)$ & $13(8,26)$ & $12(8,18)$ \\
\hline No. (\%) 6-12 months & $8(50)$ & $10(58)$ & $4(50)$ & $6(46)$ \\
\hline No. (\%) 12-18 months & $4(25)$ & $4(24)$ & $2(25)$ & $4(30)$ \\
\hline No. $(\%)>18$ months & $4(25)$ & $3(18)$ & $2(25)$ & $3(23)$ \\
\hline $\begin{array}{l}\text { Charlson Comorbidity Index Score, Median } \\
\left(P_{25}, P_{75}\right)\end{array}$ & $4(3,6)$ & $4(3,5)$ & $4(3,5)$ & $4(3,5)$ \\
\hline \multicolumn{5}{|l|}{$\begin{array}{l}\text { Canadian Study of Health and Aging Frailty } \\
\text { Scale, No. (\%) }\end{array}$} \\
\hline Very fit & $0(0)$ & $0(0)$ & $0(0)$ & $0(0)$ \\
\hline Well & $1(6.2)$ & $1(5.8)$ & $1(12.5)$ & $1(7.7)$ \\
\hline Woll with treated comorhid diceace & $3(18.7)$ & $1(5.8)$ & $1(12.5)$ & $1(7.7)$ \\
\hline Well with treated comorbid disease & $3(18.7$ & $6(35.2)$ & $1(12.5)$ & $5(38.5)$ \\
\hline Mildly frail & $4(25)$ & $6(35.2)$ & $2(25)$ & $3(23.1)$ \\
\hline Modoreter & $4(25)$ & $3(17.6)$ & $2(25)$ & $3(23.1)$ \\
\hline Coveralv frail & $1(6.2)$ & $0(0)$ & $1(12.5)$ & $0(0)$ \\
\hline 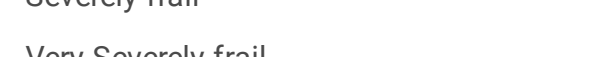 & $0(0)$ & $0(0)$ & $0(0)$ & $0(0)$ \\
\hline $\begin{array}{l}\text { Very Severely trall } \\
\text { Terminally ill }\end{array}$ & $0(0)$ & $0(0)$ & $0(0)$ & $0(0)$ \\
\hline \multicolumn{5}{|l|}{ Usual walking aids } \\
\hline None & $2(13)$ & $5(29)$ & $2(25)$ & $4(31)$ \\
\hline Single point cane & $5(31)$ & $5(29)$ & $2(25)$ & $4(31)$ \\
\hline Quad cane & $3(19)$ & $0(0)$ & $2(25)$ & $0(0)$ \\
\hline Hemi-walker & $4(25)$ & $3(18)$ & $1(13)$ & $2(15)$ \\
\hline
\end{tabular}

Page 16/24 


\begin{tabular}{|lllll|}
\hline 4-wheeled walker & $2(12)$ & $4(24)$ & $1(12)$ & $3(23)$ \\
\hline No. $(\%)$ using AFOs & $3(38)$ & $2(14)$ & $3(37.5)$ & $1(7.1)$ \\
\hline $\begin{array}{l}\text { No. }(\%) \text { with a caregiver } \\
\text { Caregiver Participants }\end{array}$ & $8(50)$ & $11(65)$ & $7(87)$ & $11(84)$ \\
\hline No. $(\%)$ of caregiver recruited & $8(100)$ & $5(55)$ & $6(85)$ & $4(85)$ \\
\hline $\begin{array}{l}\text { Caregiver role } \\
\text { Spouse/Partner }\end{array}$ & $6(75)$ & & $5(83)$ & $1(20)$ \\
\hline Child & $2(25)$ & $4(66)$ & $1(16)$ & $3(60)$ \\
\hline No. $(\%)$ female & $2(25)$ & $2(33)$ & $2(33)$ & $68(58,74)$ \\
\hline Age in years, median $\left(P_{25}, P_{75}\right)$ & $68(61,74)$ & $3(50)$ & $69(58,74)$ & $0(0)$ \\
\hline No. $(\%)$ caregivers employed & $1(8)$ & $69(63,74)$ & $1(16.6)$ & $2(40)$ \\
\hline $\begin{array}{l}\text { Time spent caregiving, no. }(\%) \\
0-9 \text { hours/week }\end{array}$ & $2(25)$ & $0(0)$ & $2(33)$ & $0(0)$ \\
\hline $\begin{array}{l}10-20 \text { hours/week } \\
>20 \text { hours/week }\end{array}$ & $1(13)$ & $2(40)$ & $0(0)$ & $3(60)$ \\
\hline
\end{tabular}

Abbreviations: $\mathrm{P}_{25}, 25^{\text {th }}$ percentile; $\mathrm{P}_{75}, 75^{\text {th }}$ percentile; no, number; $A F O$, ankle foot orthosis.

*Information missing for one participant.

${ }^{\dagger}$ Information missing for two participants.

Table 2 Completion of evaluations and falls monitoring and receipt of co-interventions 


\begin{tabular}{|c|c|c|}
\hline Protocol Element & $\begin{array}{l}\text { Immediate Group } \\
\mathrm{n}=16\end{array}$ & $\begin{array}{l}\text { Waitlist Group } \\
\mathrm{n}=17^{\star}\end{array}$ \\
\hline \multicolumn{3}{|l|}{ Participant attendance at evaluations } \\
\hline Baseline & $16(100 \%)$ & $17(100 \%)$ \\
\hline 3 months & $14(88 \%)$ & $13(76 \%)$ \\
\hline 6 months & $12(75 \%)$ & $14(81 \%)$ \\
\hline 10 months & $10(63 \%)$ & $12(71 \%)$ \\
\hline \multicolumn{3}{|l|}{ Duration of falls data collection, $\mathrm{n}(\%)$} \\
\hline 0-3 months & $1(6 \%)$ & $3(18 \%)$ \\
\hline 4-7 months & $4(25 \%)$ & $1(6 \%)$ \\
\hline 8-10 months & $11(69 \%)$ & $13(76 \%)$ \\
\hline \multicolumn{3}{|l|}{ Receipt of co-interventions, n (\%) } \\
\hline Baseline & $0(0 \%)$ & $0(0 \%)$ \\
\hline 3 months & $3(19 \%)$ & $0(0 \%)$ \\
\hline 6 months & $2(12.5 \%)$ & $4(24 \%)$ \\
\hline 10 months & $0(0 \%)$ & $0(0 \%)$ \\
\hline Caregiver attendance at evaluations & $\mathrm{L}$ & $\mathrm{n}=5$ \\
\hline Baseline & $8(100 \%)$ & $5(100 \%)$ \\
\hline 3 months & $8(100 \%)$ & $5(100 \%)$ \\
\hline 6 months & $7(87.5 \%)$ & $5(100 \%)$ \\
\hline 10 months & $6(75 \%)$ & $4(80 \%)$ \\
\hline
\end{tabular}

*2 participants withdrew after randomization.

Table 3 Characteristics of recreation and healthcare centres, program delivery staff, and TIME ${ }^{\mathrm{TM}}$ program implementation at three study sites 


\begin{tabular}{|c|c|c|c|}
\hline \multirow[t]{2}{*}{ Characteristic } & \multicolumn{3}{|l|}{ Study Site } \\
\hline & Toronto & London & Pembroke \\
\hline Population ${ }^{32}$ & 5.5 million & 366,151 & 24,017 \\
\hline \multicolumn{4}{|l|}{ Recreation centre } \\
\hline Type of organization & For-profit recreation centre & Non-profit recreation centre & For-profit fitness centre \\
\hline License signed & Yes & Yes & Yes \\
\hline Role of license signee & Managing Director & Manager & Fitness Director \\
\hline Role of program liaison & Fitness supervisor & Recreation coordinator & Fitness director \\
\hline $\begin{array}{l}\text { No. fitness instructors } \\
\text { trained }\end{array}$ & 3 & 4 & 3 \\
\hline $\begin{array}{l}\text { No. volunteers } \\
\text { (qualifications) }\end{array}$ & 2 (undergraduate students) & 1 (retired physical therapist) & 0 \\
\hline Volunteers trained & Yes & Yes & NA \\
\hline \multirow[t]{2}{*}{ Class schedule } & Mon: 10:45-11:45 am & Tues \& Thurs: & Mon \& Wed: \\
\hline & Fri: 9:30-10:30 am & 2:00-3:00 pm & 2:00-3:00 pm \\
\hline Program dates & Oct 2017-Jan 2018 & Oct 2017-Jan 2018 & Apr-Jul 2018 \\
\hline Class size (range) & $2-6$ & $2-4$ & $1-4$ \\
\hline $\begin{array}{l}\text { Instructor-plus-volunteer } \\
\text { to participant ratio }\end{array}$ & $1: 4$ or better & $1: 4$ or better & $1: 4$ or better \\
\hline $\begin{array}{l}\text { No. (\%) of } 24 \text { classes } \\
\text { delivered }\end{array}$ & $22^{*}(92)$ & $23^{*}(96)$ & $24(100)$ \\
\hline $\begin{array}{l}\text { Percent of classes } \\
\text { adhering to prescribed } \\
\text { class format }\end{array}$ & 100 & 100 & 100 \\
\hline \multirow{4}{*}{$\begin{array}{l}\text { Transportation options } \\
\text { utilized }\end{array}$} & -Participant drove & -Participant drove & -Participant drove \\
\hline & -Caregiver drove & -Caregiver drove & -Caregiver drove \\
\hline & -Public adapted transportation & - Driving service $^{\dagger}$ & - -Driving service $^{\dagger}$ \\
\hline & -Red Cross driving service ${ }^{\dagger}$ & $\begin{array}{l}\text { (no public adapted transportation } \\
\text { available) }\end{array}$ & $\begin{array}{l}\text { (no public adapted transportation } \\
\text { available) }\end{array}$ \\
\hline \multicolumn{4}{|l|}{ Healthcare centre } \\
\hline Type of organization & $\begin{array}{l}\text { Community general hospital with } \\
\text { inpatient and outpatient stroke } \\
\text { rehabilitation services }\end{array}$ & $\begin{array}{l}\text { Regional stroke centre with } \\
\text { inpatient and outpatient stroke } \\
\text { rehabilitation services }\end{array}$ & $\begin{array}{l}\text { Regional stroke centre with } \\
\text { inpatient and outpatient stroke } \\
\text { rehabilitation services }\end{array}$ \\
\hline Role of decision-maker & $\begin{array}{l}\text { Program Director, Medicine and Post } \\
\text { Acute Services }\end{array}$ & $\begin{array}{l}\text { Medical Director, Stroke } \\
\text { Rehabilitation Program }\end{array}$ & $\begin{array}{l}\text { Director, Physical Medicine and } \\
\text { Rehabilitation }\end{array}$ \\
\hline Role of program liaison & Manager of Allied Health & $\begin{array}{l}\text { Medical Director, Stroke } \\
\text { Rehabilitation Program }\end{array}$ & Vascular Health Coordinator \\
\hline $\begin{array}{l}\text { Healthcare partner } \\
\text { (mode of transportation } \\
\text { to recreation site) }\end{array}$ & $\begin{array}{l}\text { Physical therapist in outpatient } \\
\text { program (car) }\end{array}$ & $\begin{array}{l}\text { Physical therapist in outpatient } \\
\text { program (car) }\end{array}$ & $\begin{array}{l}\text { Physical therapist in outpatient } \\
\text { program (car) }\end{array}$ \\
\hline $\begin{array}{l}\text { Healthcare partner } \\
\text { oriented }\end{array}$ & Yes & Yes & Yes \\
\hline $\begin{array}{l}\text { Distance to recreation } \\
\text { centre }(\mathrm{km})\end{array}$ & $2.0 \mathrm{~km}$ & $6.1 \mathrm{~km}$ & $2.7 \mathrm{~km}$ \\
\hline $\begin{array}{l}\text { No. of } 5 \text { healthcare } \\
\text { partner visits completed }\end{array}$ & 5 & 5 & 5 \\
\hline
\end{tabular}

Abbreviations: No., number; NA, not applicable. 
${ }^{*}$ Classes cancelled due to public holidays.

${ }^{\dagger}$ Cost depended on distance travelled and ranged from $\$ 9$ to $\$ 35$ per trip.

Table 4 Scores on primary, secondary, and explanatory outcome measures by intervention group across evaluation time points 


\begin{tabular}{|c|c|c|c|c|c|c|c|c|c|c|c|c|c|c|c|c|}
\hline \multirow{4}{*}{$\begin{array}{l}\text { Measure (score } \\
\text { range) } \\
\\
\begin{array}{l}\text { SIPSO Physical } \\
(0-20)\end{array}\end{array}$} & \multirow{2}{*}{\multicolumn{8}{|c|}{$\begin{array}{l}\text { Immediate Group }(\mathrm{n}=8,6 \text { caregivers }) \\
\text { Median }\left(\mathrm{P}_{25}, \mathrm{P}_{75}\right)\end{array}$}} & \multicolumn{8}{|c|}{ Waitlist Group ( $n=13,5$ caregivers) } \\
\hline & & & & & & & & & \multicolumn{8}{|c|}{ Median $\left(\mathrm{P}_{25}, \mathrm{P}_{75}\right)$} \\
\hline & \multicolumn{2}{|c|}{ Baseline } & \multicolumn{2}{|c|}{3 months } & \multicolumn{2}{|c|}{6 months } & \multicolumn{2}{|c|}{10 months } & \multicolumn{2}{|c|}{ Baseline } & \multicolumn{2}{|c|}{3 months } & \multicolumn{2}{|c|}{6 months } & \multicolumn{2}{|c|}{10 months } \\
\hline & 7 & $\begin{array}{l}5(3 \\
15)^{*}\end{array}$ & 8 & $\begin{array}{l}8(3 \\
16)\end{array}$ & 8 & $\begin{array}{l}7(3 \\
16)\end{array}$ & 7 & $\begin{array}{l}7(5, \\
16)\end{array}$ & 13 & $\begin{array}{l}11(9 \\
16)\end{array}$ & 13 & $\begin{array}{l}11(10 \\
16)\end{array}$ & 13 & $\begin{array}{l}11(5, \\
16)\end{array}$ & 10 & $\begin{array}{l}14(9 \\
16)\end{array}$ \\
\hline $\begin{array}{l}\text { SIPSO Social } \\
(0-20)\end{array}$ & 8 & $\begin{array}{l}14 \\
(11, \\
15)\end{array}$ & 8 & $\begin{array}{l}12(10 \\
14)\end{array}$ & 8 & $\begin{array}{l}14 \\
(10, \\
16)\end{array}$ & . & $\begin{array}{l}14(8 \\
14)\end{array}$ & 13 & $\begin{array}{l}14(9, \\
17)\end{array}$ & 13 & $\begin{array}{l}13(9 \\
16)\end{array}$ & 13 & $\begin{array}{l}12(8 \\
14)\end{array}$ & 10 & $\begin{array}{l}12(9 \\
14)\end{array}$ \\
\hline NEADL (0-66) & 8 & $\begin{array}{l}31 \\
(15, \\
52)\end{array}$ & 7 & $\begin{array}{l}28(12, \\
51)\end{array}$ & 6 & $\begin{array}{l}30 \\
(17, \\
53)\end{array}$ & 7 & $\begin{array}{l}32 \\
(16, \\
49)\end{array}$ & 13 & $\begin{array}{l}39(29, \\
53)\end{array}$ & 10 & $\begin{array}{l}49(25 \\
53)\end{array}$ & 10 & $\begin{array}{l}43(23 \\
53)\end{array}$ & 11 & $\begin{array}{l}41(35, \\
50)\end{array}$ \\
\hline LSA (0-120) & 8 & $\begin{array}{l}44 \\
(27 \\
62)\end{array}$ & 8 & $\begin{array}{l}41(23, \\
72)\end{array}$ & 7 & $\begin{array}{l}33 \\
(29, \\
78)\end{array}$ & 7 & $\begin{array}{l}34 \\
(12, \\
54)\end{array}$ & 12 & $\begin{array}{l}39(21 \\
61)\end{array}$ & 13 & $\begin{array}{l}29(17 \\
52)\end{array}$ & 12 & $\begin{array}{l}39(22, \\
45)\end{array}$ & 10 & $\begin{array}{l}40(27, \\
69)\end{array}$ \\
\hline $\begin{array}{l}\text { Barthel Index } \\
(0-100)\end{array}$ & 7 & $\begin{array}{l}80 \\
(50 \\
100)\end{array}$ & 7 & $\begin{array}{l}95(75 \\
100)\end{array}$ & 8 & $\begin{array}{l}90 \\
(51, \\
98)\end{array}$ & 7 & $\begin{array}{l}95 \\
(75 \\
100)\end{array}$ & 12 & $\begin{array}{l}95(81, \\
99)\end{array}$ & 13 & $\begin{array}{l}95(83 \\
100)\end{array}$ & 13 & $\begin{array}{l}95(71 \\
100)\end{array}$ & 11 & $\begin{array}{l}95(85, \\
100)\end{array}$ \\
\hline $\begin{array}{l}\text { SIS Physical (4- } \\
\text { 20) }\end{array}$ & 8 & $\begin{array}{l}10(8, \\
15)\end{array}$ & 8 & $\begin{array}{l}10(9 \\
15)\end{array}$ & 8 & $\begin{array}{l}10(8 \\
16)\end{array}$ & 7 & $\begin{array}{l}11(8, \\
16)\end{array}$ & 13 & $\begin{array}{l}12(10 \\
15)\end{array}$ & 13 & $\begin{array}{l}14(11 \\
16)\end{array}$ & 12 & $\begin{array}{l}12(9 \\
14)\end{array}$ & 10 & $\begin{array}{l}13(9 \\
16)\end{array}$ \\
\hline $\begin{array}{l}\text { SIS Memory (7- } \\
35)\end{array}$ & 8 & $\begin{array}{l}31.5 \\
(26 \\
34)\end{array}$ & 7 & $\begin{array}{l}32(27 \\
35)\end{array}$ & 8 & $\begin{array}{l}31 \\
(27, \\
35)\end{array}$ & 7 & $\begin{array}{l}33 \\
(26, \\
35)\end{array}$ & 13 & $\begin{array}{l}29(26 \\
35)\end{array}$ & 13 & $\begin{array}{l}29(27 \\
34)\end{array}$ & 13 & $\begin{array}{l}29(23 \\
32)\end{array}$ & 10 & $\begin{array}{l}30(30, \\
31)\end{array}$ \\
\hline $\begin{array}{l}\text { SIS Mood (9- } \\
45)\end{array}$ & 8 & $\begin{array}{l}33 \\
(32, \\
34)\end{array}$ & 8 & $\begin{array}{l}32.5 \\
(28 \\
37)\end{array}$ & 8 & $\begin{array}{l}32(3 \\
35)\end{array}$ & 7 & $\begin{array}{l}31 \\
(30, \\
33)\end{array}$ & 13 & $\begin{array}{l}33(30 \\
35)\end{array}$ & 13 & $\begin{array}{l}31(29 \\
33)\end{array}$ & 13 & $\begin{array}{l}33(30 \\
36)\end{array}$ & 10 & $\begin{array}{l}33(28, \\
34)\end{array}$ \\
\hline $\begin{array}{l}\text { SIS } \\
\text { Communication } \\
(7-35)\end{array}$ & 8 & $\begin{array}{l}30 \\
(26, \\
35)\end{array}$ & 7 & $\begin{array}{l}32(26, \\
35)\end{array}$ & 8 & $\begin{array}{l}33 \\
(29 \\
35)\end{array}$ & 7 & $\begin{array}{l}32 \\
(26 \\
35)\end{array}$ & 12 & $\begin{array}{l}30(25 \\
35)\end{array}$ & 13 & $\begin{array}{l}32(26 \\
35)\end{array}$ & 13 & $\begin{array}{l}31(25 \\
34)\end{array}$ & 10 & $\begin{array}{l}33(29, \\
34)\end{array}$ \\
\hline SIS ADL (10-50) & 7 & $\begin{array}{l}31 \\
(26, \\
45)\end{array}$ & 6 & $\begin{array}{l}34(23 \\
35)\end{array}$ & 8 & $\begin{array}{l}33 \\
(22, \\
46)\end{array}$ & 7 & $\begin{array}{l}31 \\
(24, \\
45)\end{array}$ & 13 & $\begin{array}{l}39(31 \\
44)\end{array}$ & 12 & $\begin{array}{l}42(35 \\
46)\end{array}$ & 13 & $\begin{array}{l}39(24, \\
48)\end{array}$ & 10 & $\begin{array}{l}42(38, \\
44)\end{array}$ \\
\hline $\begin{array}{l}\text { SIS Mobility (9- } \\
45)\end{array}$ & 8 & $\begin{array}{l}32 \\
(24, \\
40)\end{array}$ & 8 & $\begin{array}{l}34(26 \\
41)\end{array}$ & 8 & $\begin{array}{l}30 \\
(26, \\
37)\end{array}$ & 7 & $\begin{array}{l}32 \\
(29, \\
34)\end{array}$ & 13 & $\begin{array}{l}35(28 \\
39)\end{array}$ & 12 & $\begin{array}{l}35(26 \\
41)\end{array}$ & 12 & $\begin{array}{l}31(28 \\
39)\end{array}$ & 10 & $\begin{array}{l}39(28, \\
42)\end{array}$ \\
\hline $\begin{array}{l}\text { SIS Hand } \\
\text { Function (5-25) }\end{array}$ & 8 & $\begin{array}{l}10(5 \\
23)\end{array}$ & 8 & $\begin{array}{l}17(8 \\
23)\end{array}$ & 8 & $\begin{array}{l}13(6 \\
20)\end{array}$ & t & $\begin{array}{l}11(6, \\
24)\end{array}$ & 13 & $\begin{array}{l}17(11, \\
20)\end{array}$ & 12 & $\begin{array}{l}18(13 \\
22)\end{array}$ & 13 & $\begin{array}{l}\text { 18) }(13 \\
21)\end{array}$ & 10 & $\begin{array}{l}18(14, \\
22)\end{array}$ \\
\hline $\begin{array}{l}\text { SIS } \\
\text { Participation (8- } \\
\text { 40) }\end{array}$ & 7 & $\begin{array}{l}21 \\
(17 \\
35)\end{array}$ & 8 & $\begin{array}{l}32(18 \\
34)\end{array}$ & 8 & $\begin{array}{l}23 \\
(15, \\
33)\end{array}$ & 7 & $\begin{array}{l}35 \\
(18 \\
37)\end{array}$ & 13 & $\begin{array}{l}28(24 \\
34)\end{array}$ & 12 & $\begin{array}{l}34(25 \\
38)\end{array}$ & 13 & $\begin{array}{l}30(28 \\
36)\end{array}$ & 10 & $\begin{array}{l}27(20, \\
33)\end{array}$ \\
\hline $\begin{array}{l}\text { SIS Recovery } \\
\text { VAS }(0-100)\end{array}$ & 6 & $\begin{array}{l}40 \\
(28, \\
90)\end{array}$ & 8 & $\begin{array}{l}63(46 \\
90)\end{array}$ & 8 & $\begin{array}{l}50 \\
(20, \\
94)\end{array}$ & 7 & $\begin{array}{l}60 \\
(50, \\
90)\end{array}$ & $y$ & $\begin{array}{l}75(53 \\
85)\end{array}$ & 9 & $\begin{array}{l}70(53 \\
78)\end{array}$ & 13 & $\begin{array}{l}70(53 \\
85)\end{array}$ & 10 & $\begin{array}{l}80(58, \\
90)\end{array}$ \\
\hline $\begin{array}{l}\text { EQ-5D-5L } \\
\text { Health Utility }\end{array}$ & 7 & $\begin{array}{l}0.5 \\
(0.4 \\
0.7)\end{array}$ & 8 & $\begin{array}{l}0.7 \\
(0.6, \\
0.8)\end{array}$ & 8 & $\begin{array}{l}0.6 \\
(0.5, \\
0.7)\end{array}$ & 7 & $\begin{array}{l}0.6 \\
(0.5, \\
0.8)\end{array}$ & 13 & $\begin{array}{l}0.8 \\
(0.6 \\
0.9)\end{array}$ & 13 & $\begin{array}{l}0.7 \\
(0.6 \\
0.8)\end{array}$ & 13 & $\begin{array}{l}0.8 \\
(0.5, \\
0.8)\end{array}$ & 10 & $\begin{array}{l}0.8 \\
(0.5, \\
0.8)\end{array}$ \\
\hline $\begin{array}{l}\text { EQ-5D-5L VAS } \\
(0-100)\end{array}$ & 7 & $\begin{array}{l}60 \\
(50, \\
75)\end{array}$ & 8 & $\begin{array}{l}80(70 \\
94)\end{array}$ & 8 & $\begin{array}{l}78 \\
(40, \\
84)\end{array}$ & 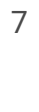 & $\begin{array}{l}75 \\
(50, \\
85)\end{array}$ & 12 & $\begin{array}{l}70(62 \\
75)\end{array}$ & 12 & $\begin{array}{l}80(67, \\
84)\end{array}$ & 13 & $\begin{array}{l}80(50, \\
80)\end{array}$ & 10 & $\begin{array}{l}80(50, \\
83)\end{array}$ \\
\hline CAS (0-102) & 6 & $\begin{array}{l}52(31 \\
, 84)\end{array}$ & 6 & $\begin{array}{l}53(35 \\
, 78)\end{array}$ & 6 & $\begin{array}{l}52(34 \\
, 83)\end{array}$ & 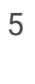 & $\begin{array}{l}33(16 \\
, 55)\end{array}$ & 5 & $\begin{array}{l}54(32 \\
, 71)\end{array}$ & 5 & $\begin{array}{l}78(33 \\
, 84)\end{array}$ & 5 & $\begin{array}{l}57(25 \\
, 75)\end{array}$ & 4 & $\begin{array}{l}60(38 \\
, 82)\end{array}$ \\
\hline $\begin{array}{l}\text { RAND Emotion } \\
(0-100)\end{array}$ & 6 & $\begin{array}{l}62(57 \\
, 76)\end{array}$ & 6 & $\begin{array}{l}64(55 \\
, 64)\end{array}$ & 6 & $\begin{array}{l}70 \\
(61 \\
, 76)\end{array}$ & 5 & $\begin{array}{l}74(49 \\
, 84)\end{array}$ & 4 & $\begin{array}{l}62(59 \\
, 68)\end{array}$ & 5 & $\begin{array}{l}76(64 \\
, 84)\end{array}$ & 5 & $\begin{array}{l}56(52 \\
, 76)\end{array}$ & 4 & $\begin{array}{l}64(40 \\
, 64)\end{array}$ \\
\hline $\begin{array}{l}\text { RAND Fatigue } \\
(0-100)\end{array}$ & 6 & $\begin{array}{l}43(25 \\
, 49)\end{array}$ & 6 & $\begin{array}{l}33(26 \\
, 39)\end{array}$ & 6 & $\begin{array}{l}35(47 \\
, 43)\end{array}$ & 5 & $\begin{array}{l}53(41 \\
, 68)\end{array}$ & 4 & $\begin{array}{l}50(44 \\
, 55)\end{array}$ & 5 & $\begin{array}{l}35(30 \\
, 40)\end{array}$ & 5 & $\begin{array}{l}50(30 \\
, 55)\end{array}$ & 4 & $\begin{array}{l}50(30 \\
, 75)\end{array}$ \\
\hline $\begin{array}{l}\text { Berg Balance } \\
\text { Scale }(0-56)\end{array}$ & 8 & $\begin{array}{l}35 \\
(22,\end{array}$ & 7 & $\begin{array}{l}40(33, \\
50)\end{array}$ & 7 & $\begin{array}{l}49 \\
(26,\end{array}$ & $f$ & $\begin{array}{l}45 \\
(26,\end{array}$ & 13 & $\begin{array}{l}44(27 \\
49)\end{array}$ & 13 & $\begin{array}{l}47(30 \\
52)\end{array}$ & 11 & $\begin{array}{l}46(23 \\
52)\end{array}$ & 11 & $\begin{array}{l}48(38, \\
52)\end{array}$ \\
\hline
\end{tabular}




\begin{tabular}{|c|c|c|c|c|c|c|c|c|c|c|c|c|c|c|c|c|}
\hline & & 48) & & & & 52) & & 51) & & & & & & & & \\
\hline $\begin{array}{l}\text { ABC Scale (0- } \\
100)\end{array}$ & 7 & $\begin{array}{l}39 \\
(28 \\
76)\end{array}$ & 8 & $\begin{array}{l}61(32, \\
79)\end{array}$ & 8 & $\begin{array}{l}49(32 \\
71)\end{array}$ & 7 & $\begin{array}{l}53 \\
(34 \\
83)\end{array}$ & 12 & $\begin{array}{l}\text { 65(57, } \\
82)\end{array}$ & 12 & $\begin{array}{l}72(60, \\
91)\end{array}$ & 13 & $\begin{array}{l}63(34 \\
77)\end{array}$ & 10 & $\begin{array}{l}69(53, \\
83)\end{array}$ \\
\hline $\begin{array}{l}30-\sec \text { Sit to } \\
\text { Stand }\end{array}$ & 8 & $\begin{array}{l}3(0, \\
8)\end{array}$ & 7 & $\begin{array}{l}6(2, \\
9)\end{array}$ & 7 & $\begin{array}{l}5(0, \\
7)\end{array}$ & 6 & $\begin{array}{l}6(0, \\
9)\end{array}$ & 12 & $\begin{array}{l}6(2, \\
8)\end{array}$ & 13 & $\begin{array}{l}6(0) \\
10)\end{array}$ & 11 & $\begin{array}{l}5(4, \\
9)\end{array}$ & 10 & $\begin{array}{l}7(3, \\
9)\end{array}$ \\
\hline $\begin{array}{l}\text { 10-m walk test } \\
(\mathrm{m} / \mathrm{s})\end{array}$ & 8 & $\begin{array}{l}0.5 \\
(0.1 \\
0.9)\end{array}$ & 8 & $\begin{array}{l}0.5 \\
(0.1 \\
1.2)\end{array}$ & 7 & $\begin{array}{l}0.5 \\
(0.1 \\
1.1)\end{array}$ & 7 & $\begin{array}{l}0.3 \\
(0.1 \\
0.9)\end{array}$ & 13 & $\begin{array}{l}0.7 \\
(0.5, \\
0.9)\end{array}$ & 13 & $\begin{array}{l}0.8 \\
(0.5 \\
1.1)\end{array}$ & 11 & $\begin{array}{l}0.7 \\
(0.3, \\
0.8)\end{array}$ & 11 & $\begin{array}{l}0.8 \\
(0.6, \\
1.1)\end{array}$ \\
\hline $\begin{array}{l}\text { 6-minute walk } \\
\text { test }(\mathrm{m})\end{array}$ & 8 & $\begin{array}{l}156.5 \\
(37.0 \\
319.5)\end{array}$ & 8 & $\begin{array}{l}129.5 \\
(101.5 \\
300.0)\end{array}$ & 7 & $\begin{array}{l}200.5 \\
(81.5 \\
299.5)\end{array}$ & 6 & $\begin{array}{l}120.0 \\
(95.0 \\
300.0)\end{array}$ & 13 & $\begin{array}{l}240.6 \\
(191.0 \\
299.0)\end{array}$ & 13 & $\begin{array}{l}180.0 \\
(112.0 \\
300.0)\end{array}$ & 11 & $\begin{array}{l}174.0 \\
(132.4 \\
300.0)\end{array}$ & 10 & $\begin{array}{l}179.0 \\
(114.0 \\
364.0)\end{array}$ \\
\hline $\begin{array}{l}\text { Trail making } \\
\text { test A (sec) }\end{array}$ & 8 & $\begin{array}{l}55.9 \\
(45.0 \\
187.5)\end{array}$ & 8 & $\begin{array}{l}55.5 \\
(45.8 \\
275)\end{array}$ & 7 & $\begin{array}{l}47.0 \\
(42.0 \\
95.0)\end{array}$ & 7 & $\begin{array}{l}48.9 \\
(44.0 \\
120.0)\end{array}$ & 13 & $\begin{array}{l}65.0 \\
(37.8 \\
89.5)\end{array}$ & 11 & $\begin{array}{l}61.0 \\
(42.5 \\
121)\end{array}$ & 12 & $\begin{array}{l}51.1 \\
(40.1 \\
170.0)\end{array}$ & 11 & $\begin{array}{l}53.9 \\
(36.0 \\
95.8)\end{array}$ \\
\hline $\begin{array}{l}\text { Trail making } \\
\text { test } B(\mathrm{sec})\end{array}$ & 8 & $\begin{array}{l}169.0 \\
(85.3 \\
300)\end{array}$ & 8 & $\begin{array}{l}129.5 \\
(101.5 \\
300.0)\end{array}$ & 7 & $\begin{array}{l}167.0 \\
(61.7 \\
298.0)\end{array}$ & 7 & $\begin{array}{l}120.0 \\
(95.0 \\
300.0)\end{array}$ & 13 & $\begin{array}{l}202.0 \\
(100.5 \\
300.0)\end{array}$ & 11 & $\begin{array}{l}180.0 \\
(112.0 \\
300.0)\end{array}$ & 12 & $\begin{array}{l}158.3 \\
(130.2 \\
300.0)\end{array}$ & 11 & $\begin{array}{l}142.0 \\
(91.9 \\
300.0)\end{array}$ \\
\hline GDS (0-15) No. & 8 & & 8 & & 8 & & 7 & & 12 & & 12 & & 13 & & 10 & \\
\hline Normal (0-4) & & & & $\begin{array}{l}12.5 \\
(1)\end{array}$ & & $1(0)$ & & $\begin{array}{l}12.5 \\
(1)\end{array}$ & & $1(0)$ & & $\begin{array}{l}15.3 \\
(2)\end{array}$ & & $7.6(1)$ & & $0(0)$ \\
\hline Mild (5-8) & & $75(6)$ & & $75(6)$ & & $\begin{array}{l}62.5 \\
(5)\end{array}$ & & 37.5 & & $\begin{array}{l}53.8 \\
(6)\end{array}$ & & 46.1 & & $\begin{array}{l}69.2 \\
(9)\end{array}$ & & $\begin{array}{l}70(7) \\
30(3)\end{array}$ \\
\hline $\begin{array}{l}\text { Moderate (9- } \\
\text { 11) }\end{array}$ & & $0(0)$ & & $\begin{array}{l}12.5 \\
(1)\end{array}$ & & $25(2)$ & & $25(2)$ & & $\begin{array}{l}15.3 \\
(2)\end{array}$ & & $\begin{array}{l}30.7 \\
(4)\end{array}$ & & $23(3)$ & & $0(0)$ \\
\hline Severe (12-15) & & & & $0(0)$ & & $(1$ & & $\begin{array}{l}12.5 \\
(1)\end{array}$ & & $\begin{array}{l}30.7 \\
(4)\end{array}$ & & $0(0)$ & & & & \\
\hline
\end{tabular}

Abbreviations: SIPSO, subjective index of physical and social outcome; NEADL, Nottingham extended activities of daily living; LSA, lifespace assessment; SIS, stroke impact scale; ADL, activities of daily living; VAS, visual analog scale; EQ-5D-5L, EuroQol-5D, five-level; CAS, caregiver assessment scale; $A B C$, activities-specific balance confidence; GDS, geriatric depression scale. Within each timeline column, the first subcollumn represents the number of participants for which data were available.

Table 5 Proposed revisions to the study protocol based on pilot results 
Challenges during pilot study

\section{Recruitment}

- Unable to achieve recruitment target of 20 per site.
Proposed changes to study protocol

- Engage a member of the stroke team preferably in the out-patient department, known to patients, to refer people to the study.

- For prospective recruitment, ensure access to patients near the time of discharge.

- Highlight the type and benefits of exercises in the program in recruitment materials.

- Consider targeting other clinical populations to boost recruitment given the exercise program is not specific to any health condition.

- Some participants could not fully engage with the exercises due to a low level of physical function,

- Revise eligibility criteria that require individuals to have the capacity to perform sit-to-stand independently, walk 10 metres independently with or without a walking aid but without assistance or supervision of another individual, and pass a cognitive screen.

- Only $68 \%$ of caregivers were recruited.

- Develop caregiver-specific recruitment materials that highlightthe role of caregivers in the exercise program and potential benefits for the caregiver.

\section{Length of wait time for control group}

- 12-month waitlist period was too long and led to drop-outs and potentially co-interventions.

- Reduce the wait time in the control group to 6 months.

\section{Evaluations}

- Inclement weather and inadequate access to transportation were perceived as barriers to attending the exercise program and evaluations.

- Evaluations was considered lengthy.

- Monthly follow-up calls for falls monitoring

- Schedule evaluations and intervention periods during good-weather months if possible.

- Provide participants with information about transportation services available in their region at the time of recruitment.

- Budget for reimbursement for parking, adapted transportation, and driving services for remote areas.

- Provide participants with gift cards as an incentive to attend evaluations, and the option to receive an evaluation summary.

- Streamline the number of study measures to reduce evaluation length.

- Provide flexible data collection options for those unable to attend in person e.g. administer self-report measures by telephone.

- Remove monthly falls monitoring given the exercise program was deemed safe.

\section{Fitness instructor training}

- Fitness instructor turnover necessitated identification and training of new instructors.

- Train 3-5 instructors annually per site to improve instructor availability and mitigate potential turnover.

Program delivery

- Participants found it distracting when other classes were being run in the same room and when rooms and class times changed between sessions.

- Ensure no other classes are being run in the same room.

- Recommend using the same room and time for both classes each week.

\section{Potential effect}

- Improvement on measures of walking capacity over the 3 -month exercise program were not observed.

- In new sites, fitness instructors and volunteers deliver the TIME ${ }^{T M}$ program for the first time during the experimental phase and may lack the expertise to progress participants.
- Incorporate additional practice of exercises for fitness instructors in the training workshop.

- Have an initial group of exercise participants start the program prior to randomization.

\section{Figures}




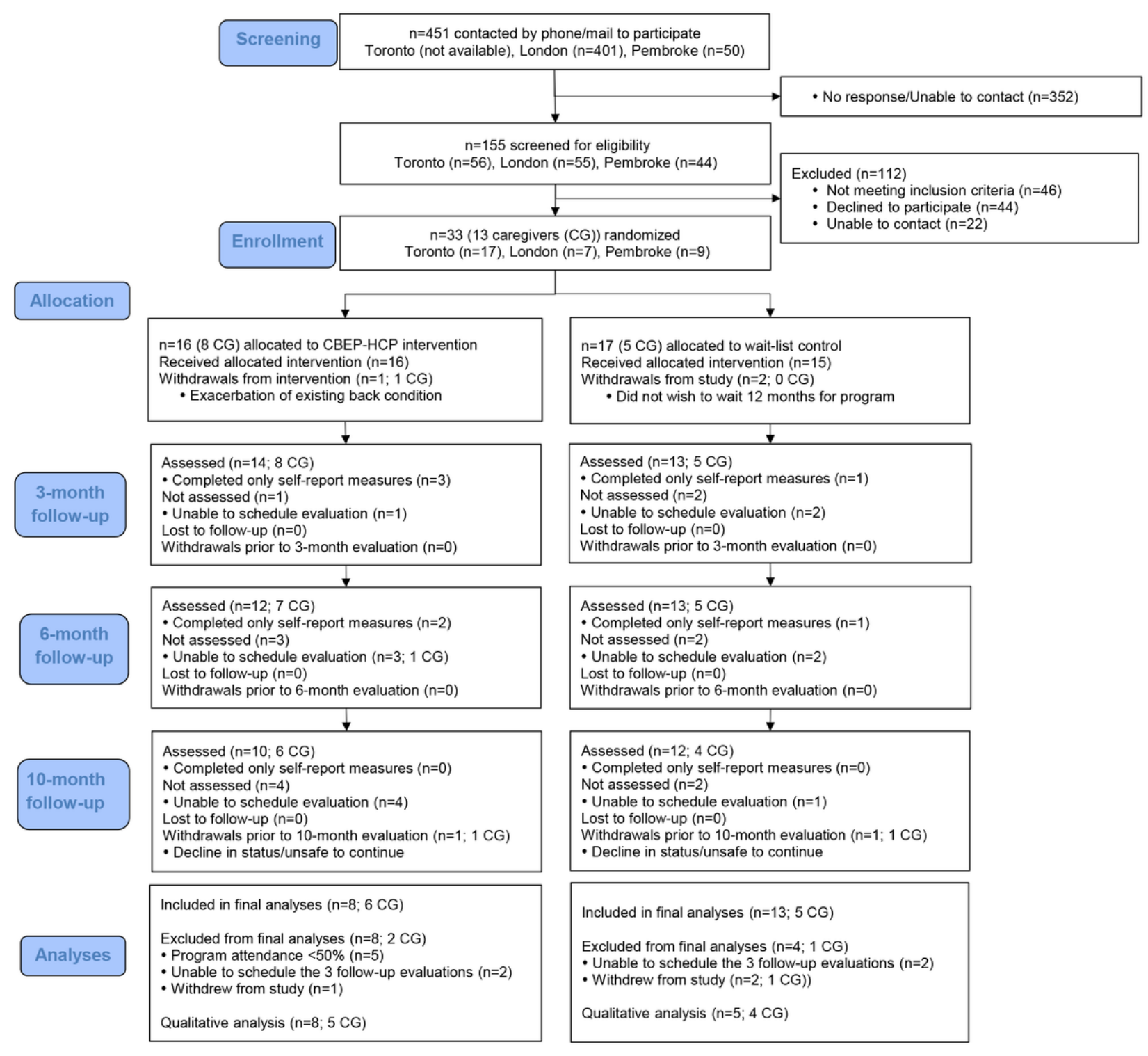

Figure 1

CONSORT flow diagram.

\section{Supplementary Files}

This is a list of supplementary files associated with this preprint. Click to download.

- CONSORTextensionforPilotandFeasibilityTrialsChecklist.doc 